\title{
La relación genética e histórica entre el conductismo y el constructivismo pedagógicos como fundamento epistémico de la formación militar
}

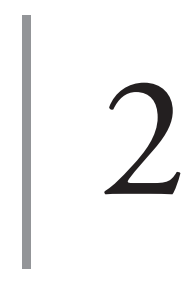

https://doi.org/10.21830/9789585380271.02

\author{
Martha Hortensia Arana Ercilla ${ }^{1}$ \\ Vicente Hernán Ibarra Argoty ${ }^{2}$ \\ Escuela Militar de Cadetes "General José María Córdova"
}

En este capítulo se presenta la fundamentación epistémica, genética e histórica que permite establecer la relación entre el conductismo y el constructivismo en la educación militar. Con este propósito se puntualiza en contenidos como la reflexividad, el eclecticismo reflexivo, el enfoque histórico-genético y las corrientes e ideas pedagógicas de la Modernidad, como contexto en que nacen el conductismo y el constructivismo pedagógicos.

Además, se exponen los enfoques teóricos del estudio desde la perspectiva de la integralidad del ser humano y del conocimiento, en correspondencia con el llamado giro epistemológico de las ciencias sociales, en la pedagogía y en las ciencias militares. Asimismo, desde el enfoque histórico-genético de la dialéctica, se abordan las categorías relación y eclecticismo reflexivo, para analizar las ideas pedagógicas objeto de estudio desde la reflexividad.

1 PhD en Educación de la Universidad Tecnológica de La Habana y posdoctorado en Educación de la Universidad Pedagógica de Colombia. Economista de la Universidad de La Habana. Docente investigadora de la Facultad de Ciencias Militares de la Escuela Militar de Cadetes “General José María Córdova”.

2 Oficial de la Reserva Activa del Ejército Nacional de Colombia. Profesional en Ciencias Militares de la Escuela Militar de Cadetes "General José María Córdova”. Magíster en Análisis y Prevención del Terrorismo de la Universidad Rey Juan Carlos, Espańa. Abogado de la Universidad La Gran Colombia. Docente investigador de la Facultad de Ciencias Militares de la Escuela Militar de Cadetes “General José María Córdova”. 


\section{Unidad dialéctica del conocimiento}

El propósito de este apartado es profundizar en las posiciones teóricas que nutren la investigación y precisar sus sistemas conceptuales, ya sea desde la epistemología general que asumió, la cual corresponde a la comprensión que se tiene del conocimiento y de la naturaleza humana, o desde el paradigma relacionista e integracionista, resultado de los avances de la ciencia y en particular de las ciencias sociales. Esta mirada epistémica cambia la perspectiva de otros conocimientos, entre ellos la pedagogía y las ciencias militares, a través de conceptos como relación y reflexividad, los cuales permiten establecer epistemológicamente la mixtura del modelo pedagógico en estudio, que relaciona el constructivismo con el conductismo pedagógicos impregnados por el contexto militar.

Para ello, se toma como punto de partida el reconocimiento de las nuevas formas de comprensión del mundo que se han derivado de las amplias discusiones en las ciencias, específicamente en las ciencias sociales, a partir de finales de la década de los años cincuenta del siglo pasado, lo que se ha conocido como la crisis del modelo de ciencia y del método científico clásicos para las ciencias sociales.

Respecto a la mirada sobre el ser humano, se asume su complejidad biopsicosocial y cultural, y la reconfiguración del sujeto como transformador, lo cual implica, entre otras cosas, que sea considerado el centro de la educación. Esta tendencia se evidencia en las ciencias sociales como el "retorno a la noción de sujeto", lo cual significa que se sitúa su acción en el contexto específico y el momento histórico. En esta comprensión se destacan Pierre Bourdieu, Edgar Morín, Jean-Marie Schaeffer, Immanuel Wallerstein, Jesús Martin Barbero, entre otros, que se alejan de los dualismos y reduccionismos.

Esta concepción epistémica se apoya en los enfoques y las perspectivas actuales de la ciencia y, en particular, de los avances científicos y tecnológicos de la termodinámica, la biología molecular, la astronomía, las ciencias cognitivas y los estudios del cerebro. Entre los aspectos que caracterizan los cambios están la recuperación de la noción de totalidad y de sentido holístico; el rescate de la postura ético humanista; la transdisciplinariedad; la comprensión de la complejidad y la reflexividad, entre otros (Espina, 2004). De esta manera, constituye la oportunidad de romper con las llamadas "dos culturas", 
la socio-humanista y la científico-tecnológica, separadas por la exactitud objetiva y la rigurosidad de una, y lo interpretativo y subjetivo de la otra.

Esta ruptura posibilita la integración del conocimiento mediante la relación de lo objetivo y lo subjetivo; lo racional y lo emocional, lo social y lo biológico, con lo cual se inicia una revolución en el pensamiento epistémico. Se trata de pensar y accionar de forma diferente en las ciencias sociales y en su relación con otros sistemas de conocimientos como resultado de la crítica a la ciencia clásica, tradicionalista, cerrada, neutral. Como consecuencia, se derriban creencias y mitos sobre el conocimiento científico, "el mito sobre la separación sujeto-objeto y de la realidad como externalidad al ser humano" (Espina, 2004, p. 37), para producir nuevas perspectivas, entre ellas la capacidad transformadora de la acción humana consciente, desarrollada por el filósofo español Quintanilla (1999).

La nueva comprensión sobre el ser humano que de allí se deriva trata de la visión integrada de la identidad humana o naturaleza humana, que sustituye el enfoque segregacionista cartesiano, antropocentrista, por el de la dialéctica y la complejidad de la cosmovisión del mundo, que niega la llamada excepcionalidad humana. Entre los filósofos que argumentan esta perspectiva se halla Jean Marie Schaeffer (2009), quien reconoce la integralidad del ser humano como bio-psico-social-cultural, cuestión ya planteada por otros filósofos y estudiosos de la biología y la conducta humana. Al respecto, el autor plantea este interrogante:

¿Cómo es posible que los avances importantes en el conocimiento del ser humano, aportados por la biología, la neurología, la etología o la psicología, no hayan sido acogidos por los investigadores en ciencias sociales, ni por los filósofos, ni los investigadores en el campo de la cultura, como algo que hace factible el desarrollo de un modelo integrado sobre el estudio de lo humano? (Schaeffer, 2009, p. 14)

El paradigma integracionista del conocimiento, conocido como de unidad del conocimiento, deviene de los enfoques actuales sobre la convergencia entre las diferentes disciplinas científicas, de la interconexión, por una parte, entre ciencia y tecnología a través de la tecnociencia, y, por otra, entre la ciencia, la tecnología y las humanidades, con lo cual se supera el enfoque disciplinar y limitante de las llamadas "dos culturas" (Snow, 1977) que requiere la pedagogía y las ciencias militares. Este paradigma representa la interdisciplinariedad en un sentido amplio, entre las ciencias sociales y otras ciencias, que 
para muchos estudiosos es una vuelta a una unidad del conocimiento diferente, no reducido a la física. La esencia está en la dinámica de la interrelación de la ciencia, la tecnología y la sociedad, la cual permite evidenciar la presencia de los conocimientos científico-tecnológicos en todos los aspectos de la vida humana. De esta manera, se fundamenta una nueva visión de estos elementos como cultura, para superar la imagen tradicional, intelectualista y neutral anterior, y se destaca su naturaleza social. Así pues, los denominados Estudios de Ciencia, Tecnología y Sociedad (Стs) fomentan una nueva imagen de la ciencia y la tecnología como fenómenos sociales y culturales, transformando a su vez el lugar de las ciencias sociales en el resto de conocimientos.

En otro orden de ideas, esta unidad del conocimiento no solo ha permitido conocer más a los seres humanos, su origen, naturaleza y cultura, sino también su medio natural. Así, Gell-Mann (1995) señala que esta unidad

conlleva el descubrimiento de conexiones entre hechos e ideas que a simple vista parecen muy alejados entre sí, que parecería que no tienen relación. Más aún, está empezando a dar respuesta a algunas de las preguntas que muchos de nosotros, científicos o no, continuamos haciéndonos sobre el verdadero significado de lo simple y lo complejo. En la actualidad bien se conoce que la red de relaciones y conexiones entre los seres humanos consigo mismos, con la biósfera del planeta y con el cosmos, es tan simple y compleja, que todos los elementos, situaciones y fenómenos se influyen mutua y recíprocamente. (p. 13)

Esta tendencia de romper con las separaciones, aislamientos y paradigmas estrechos se ha entendido de diferentes maneras, de forma que han surgido varias posiciones epistemológicas, entre las cuales las más destacadas son la complejidad y el holismo. La irrupción del paradigma de la complejidad y del pensamiento complejo, desarrollada por Edgar Morín, significó un fuerte debate en las ciencias sociales —especialmente en la epistemología y la pedagogía - debido a su crítica a la racionalidad en las ciencias sociales como certificación de lo que plantean las ciencias naturales, así como por su propuesta de que es necesario el diálogo interdisciplinario.

De acuerdo con Barberousse (2008), este paradigma intenta

articular y contextualizar las culturas científicas, las culturas de las humanidades y las culturas artísticas. Para llevar adelante tal propósito, se basó en la integración de ideas, conceptos y nociones provenientes de diversas fuentes teóricas. El abordaje de la complejidad ha requerido de la resignificación dialéctica y creativa 
del legado de dichas teorías en una nueva síntesis que, al mismo tiempo que las integra, las eleva a un nivel cualitativamente distinto y original. (p. 95)

Esta idea hace referencia a la capacidad de conectar diferentes dimensiones de la realidad, la cual se ha caracterizado por ir adquiriendo cada vez más conocimientos, a medida que la humanidad ha ido progresando y evolucionando. La realidad se podría comparar con un tejido, compuesto por múltiples tejidos y, por tanto, algo realmente complejo, que requiere de la capacidad humana de reflexividad, la cual debe ser educada y a la que Morín (1998) denominó pensamiento complejo:

Nunca pude, a lo largo de toda mi vida, resignarme al saber parcelado, nunca pude aislar a un objeto de estudio de su contexto, de sus antecedentes, de su devenir. He aspirado siempre a un pensamiento multidimensional. Nunca he podido eliminar la contradicción interior. (Morín, 1998, p. 22)

Por ejemplo, un humano es un ser biológico, al mismo tiempo es un ser cultural, meta-biológico que vive en un universo de lenguaje, ideas y conciencia. El paradigma de simplificación obliga a desunir, a reducir, a tomar la parte de lo complejo para su análisis, y luego integrarla al todo, pero no niega ese todo complejo como tal, como tampoco lo conoce. Entonces se estudia al humano biológico en el departamento de biología y de medicina, como un ser anatómico, fisiológico, etc.; culturalmente, en su historia y contexto político. Las emociones y cogniciones de la psiquis en el área de psicología. Entonces es posible inferir que la complejidad coadyuva a la unidad del conocimiento, pero no ofrece el elemento dialéctico para la unidad, pues se puede olvidar en el ejemplo anterior que lo uno no existe sin lo otro; más aún, que uno es, al mismo tiempo, el otro, si bien son tratados con términos y conceptos diferentes. Se colige que la suma de los estudios parciales de un sistema complejo no puede dar la idea del comportamiento del todo, sino que se requiere de la unidad del conocimiento como dialéctica científica (Arana, 2018b, p. 43). Como señala Zemelman (1992):

Comprender la esencia del conocimiento depende de entender su relación con lo interno y externo al ser humano. El significado epistemológico de tomar la realidad material como punto de partida y como unidad y totalidad a la cual pertenecemos, permite hablar de la unidad del conocimiento como acción de lo humano, y entender el proceso del conocer y sus resultados [...]. El reto consiste en plantear la construcción de un conocimiento que no deje fuera, 
por su afán y precisión formales, regiones de la realidad significativas para la definición de prácticas de transformación. (p. 48)

A manera de síntesis, esta unidad del conocimiento tiene lugar en el enfoque dialéctico de las relaciones entre los distintos conocimientos científicos; entre los diferentes tipos de conocimientos (artístico, moral, científico, técnico, etc.); en la comprensión del conocimiento como resultado, proceso y actividad; en las relaciones entre lo objetivo y lo subjetivo, lo material y lo ideal, la teoría y la práctica, lo individual y lo social, y lo biológico y lo cultural. La unidad del conocimiento significa tener en cuenta sus dimensiones: como resultado (teorías, conceptos, principios, valores, experiencias, invenciones e innovaciones); como actividad o proceso (pensamientos, emociones, relaciones, razonamientos y prácticas). La unidad del conocimiento es una concepción sobre la realidad, es una actitud del ser humano; es un método y una práctica (Arana, 2018b, p. 44).

El proceso de unidad del conocimiento es multifactorial, ascendente, descendente, horizontal, transversal e interdisciplinario. Además, relaciona e integra de manera dialéctica y transformadora los diferentes conocimientos, condición que fundamenta la búsqueda de armonía de la cultura material con la espiritual, entre las ciencias sociales y las naturales. El espejo roto de la separación de las ciencias y de la especialización está en proceso de recomposición hacia su unidad.

Particularmente, uno de los objetivos de la unidad del conocimiento es que haya una cosmovisión global. Para ello es menester que la cultura material y espiritual reencuentren el equilibrio con un nuevo humanismo a la altura de nuestro tiempo, que encare sin prejuicios los problemas y retos actuales, y prospecte el futuro.

La unidad del conocimiento científico se manifiesta, ante todo, en que lo social no está desligado de la naturaleza, menos de la naturaleza humana. Lo social es, en esencia, lo natural, pero transformado adecuadamente en el curso de la actividad consciente y motivada de los humanos:

La condición humana es la frontera más importante de las ciencias naturales. Y al revés, el mundo material que han puesto al descubierto las ciencias naturales es la frontera más importante de las ciencias sociales y las humanidades. El argumento de la consiliencia puede destilarse como sigue: las dos fronteras son la misma. (Wilson, 1999, p. 391) 
Entender la realidad objetiva o subjetiva no se reduce a conocer la estructura de sus componentes o la suma de estos. Es fundamental comprenderla y conocerla en la dialéctica de sus procesos, complejidad y simplicidad, regularidad y aleatoriedad, orden y desorden, singularidad y totalidad, siempre dinámicas en cambios y transformaciones internas y externas, en todas sus relaciones y dimensiones, incluido el sujeto humano, como integrante y transformador de la naturaleza.

Este enfoque epistemológico aboga por el reconocimiento de la ciencia y el método científico, no como único, sino como "los métodos científicos", los cuales también hoy se enriquecen, no solo por las diferencias entre los tipos de conocimientos y sus requerimientos, sino también por los cambios que estos producen en las formas de pensar y los medios para hacerlo, como las tecnologías de la información, y el lugar que se le da al sujeto productor del conocimiento. Este paradigma es actualmente una alternativa diferente al paradigma "posmoderno", donde no se reconoce la realidad ni el conocimiento general y particular, sino el singular y del sujeto, de tal manera que se comprende el conocimiento como un entramado de "discursos" y "textos", de corte subjetivista, caracterizado por el relativismo y el todo vale.

Por esta razón, Olivé (2007), reconocido experto en filosofía y epistemología de la ciencia y la tecnología, destaca la necesidad de formar integralmente a los nuevos profesionales, científicos e ingenieros, de tal modo que puedan cooperar y trabajar en equipos interdisciplinarios, con alto nivel de responsabilidad e innovación. Al respecto, el autor señala:

Para cumplir con el nuevo contrato social ya no es suficiente impartir una buena enseñanza básica de los conocimientos científicos ni que solo se popularicen sus contenidos [...]. También se requieren una más amplia y mejor comprensión, y capacidad de evaluación de las virtudes y potencialidades de la ciencia y la tecnología; asimismo, se deben conocer e investigar los riesgos de sus aplicaciones y cómo vigilarlos y controlarlos. (Olivé, 2007, p. 42)

Esta mirada epistémica produce un cambio en la metodología de la investigación de las ciencias sociales hacia estrategias, métodos y técnicas cualitativas, las cuales se caracterizan por ser dinámicas y flexibles, pero también rigurosas, así como por estar muy orientadas al proceso. La investigación cualitativa 
requiere de la flexibilidad y el dinamismo para que el proceso de investigación se vaya ajustando a las propias necesidades de la realidad social estudiada, que de por sí es histórica, cambiante, diferenciada y singular en dependencia del contexto. Esta flexibilidad requiere de una reflexividad o actitud crítica sobre aquellas decisiones que se van adoptando para salvaguardar la rigurosidad y congruencia metodológica, así como la credibilidad de los resultados (González, 2009).

\section{Reflexividad y eclecticismo reflexivo}

En este orden de ideas sobre la unidad dialéctica del conocimiento como enfoque epistémico, para fundamentar la relación entre el conductismo y el constructivismo pedagógicos se deben considerar dos conceptos: la reflexividad y el eclecticismo reflexivo, los cuales están inmersos en el giro epistemológico de las ciencias sociales y en particular en la pedagogía, pues permiten romper con los paradigmas tradicionalistas y sus modelos establecidos en la educación. De esta manera, es posible conjugar diferentes referentes teóricos y consolidar propuestas auténticas y apropiadas tanto a los contextos específicos, como a los sujetos que allí actúan, lo cual permite excluir dinámicas de repetición de modelos o propuestas pedagógicas ajenas a los contextos. No se trata de una combinación acrítica o mezcla de ideas, sino de crear e innovar con propuestas pedagógicas, desde la historia y la epistemología, que hagan posible una reflexión rigurosa de la relación entre lo común y lo diferente, así como entre lo histórico y lo genético.

El eclecticismo es un concepto proveniente de la escuela ecléctica de Grecia en el siglo II a. C., anterior a los presocráticos. Es una tendencia de las escuelas del estoicismo, epicureísmo y escepticismo, que tienen en común que el ideal de la vida humana es la felicidad y las pasiones, con el propósito de volver al ser humano indiferente ante los problemas de la vida, para lo cual se apartan de los dilemas y fundamentos teóricos. Es un enfoque que se basa en la escogencia de aspectos de diferentes teorías, estilos e ideas sobre un tema de estudio de la realidad. Con este sentido se toma el eclecticismo como concepto epistémico para investigar realidades sociales con múltiples interpretaciones y 
comprensiones dadas por sus diferentes contextos y fines, de tal manera que se crean ideas y sistemas filosóficos que permiten proponer soluciones propias y originales. También puede referirse a formas de vida, creencias religiosas, sincretismos, arquitecturas y arte.

Por su parte, la reflexividad consiste en la capacidad humana de reflexión, análisis y pensamiento crítico, que está presente en las interacciones sociales. Es la acción intelectual por la cual el sujeto tiene conciencia de la realidad, desde la razón y la emoción. Desde el punto de vista de la dialéctica, se refiere a la relación causa-efecto como proceso. Se conecta con el sentido común, al pensamiento crítico, no solo hacia fuera, sino hacia dentro de sí mismo, a lo que se le denomina introspección.

La reflexividad está fuertemente enlazada con la flexibilidad. En la investigación cualitativa, esta permite la flexibilidad del proceso. Con base en el lugar que ocupa la subjetividad de las personas, no como subjetivismo, sino como el reconocimiento de las intencionalidades del investigador, se convierte en una estrategia y en una técnica de indagación. La reflexividad puede ser definida como una conversación interna con uno mismo en torno a la experiencia del proceso de investigación, al mismo tiempo que este se va desarrollando (Coffey \& Atkinson, 2005).

En las ciencias económicas, especialmente en las operaciones financieras, Soros (2014) desarrolló la teoría de la reflexividad en la década de los años setenta y ochenta, para negar el equilibrio de los mercados, reconocida por la teoría económica clásica del liberalismo y por la economía cuantitativa del equilibrio. Con esto buscaba destacar la influencia que tiene la reflexividad de los agentes económicos — a través de sus percepciones y preferencias- en determinada situación económica, lo cual conduce a la modificación de lo objetivamente esperado; es decir, se pregunta cómo la acción humana puede determinar los precios del mercado y conducir, por ejemplo, a una depresión económica (Martínez, 2004).

Soros (2014) plantea que en las situaciones sociales y económicas en general rige el principio de reflexividad, según el cual los sujetos implicados desempeñan dos funciones: una función cognitiva y una función de participación o manipulación. La primera se refiere a la comprensión que los parti- 
cipantes poseen de las coyunturas en las cuales se encuentran. La segunda consiste en las acciones intencionadas que realizan de acuerdo con su percepción de la realidad. Soros (2014) añade que en ambas funciones los agentes son inevitablemente falibles cuando toman decisiones, y que la reflexividad se prefiere cuando esta acción se considera adecuada tras un análisis.

La teoría económica afirma que los mercados alcanzan el equilibrio cuando el coste marginal de producción es igual a la utilidad marginal del comprador, e igual a su vez al precio del mercado. Esta situación maximiza el beneficio del conjunto de los participantes. Esta teoría supone que las curvas de oferta y demanda son independientes, y que existe un conocimiento perfecto del mercado. Por su parte, la teoría de la reflexividad y de la falibilidad niegan que ello se cumple con tal exactitud, puesto que existe el riesgo de que el mercado se comporte de forma imprevisible, como en realidad sucede en los procesos de expansión-explosión.

Luego de esta ilustración desde las ciencias económicas, se hace necesario destacar que la reflexividad está presente en toda la vida del ser humano, en sus acciones y decisiones. La reflexividad afecta aquellos fenómenos sociales en que la acción humana está presente.

En la bioética, lo anterior se expresa en los diferentes enfoques reflexivos, que van construyendo posiciones más elaboradas en este sistema de conocimiento que integra varias disciplinas. De acuerdo con Potter (1971), el desarrollo de la bioética ha tenido tres momentos: puente, global y profunda. La bioética puente surge de la necesidad de superar la dificultad en la comunicación entre la cultura científica y la humanista, lo que en este escrito se ha denominado las "dos culturas" (Snow, 1977), concerniente con el lugar que empiezan a ocupar las humanidades en la ciencia y en las deontologías profesionales, luego de lo ocurrido en la Segunda Guerra Mundial.

Posteriormente, Potter (1971) reflexiona sobre la educación. Ya para ese momento los Estudios de CTS en Europa tienen incidencia sobre la educación científico-tecnológica, basada en la inclusión de una comprensión nueva de la ciencia y la tecnología, así como de su relación coherente con la ética aplicada y las metodologías deliberativas en la investigación científica. De ahí que este autor desarrolle una metodología para la toma de decisiones a escala 
general, que debe ser considerada y apropiada para cada disciplina en particular y contexto. Precisamente por este camino se crea la bioética profunda, que tiene que ver con métodos y lógicas de pensamiento crítico-valorativo sobre los problemas más generales de la humanidad, consistente en un conocimiento reflexivo orientado a la ética de la vida, que desborda el conocimiento de la medicina y la biología. Al respecto, Freydell (2020) señala:

Los distintos enfoques que han llevado a un desarrollo de la bioética parten de interpretaciones del sujeto y del mundo desde una ontología del ser específica, que en muchos casos terminan cerrándose en sí mismas. Esto presenta dificultades a la hora de compartir las fronteras del conocimiento entre enfoques. Surgen diferentes posibilidades de interpretación y actuación ante una misma situación, quedando atorados estos diferentes puntos de vista morales, como dilemas que obstaculizan la toma de decisión. Se requieren formas alternativas de pensar la vida y el ser, que ayuden a superar estos cerramientos, y ofrecer cabida a las expresiones del lenguaje a través de las cuales la experiencia de vida del hombre se manifiesta de múltiples formas y significados, sin establecerse un dilema ante la necesidad de una solución única. (p. 24)

De esta manera, el eclecticismo reflexivo constituye una propuesta epistémica que trasciende la formalidad de las propuestas teóricas o los lineamientos del campo, atendiendo a diferentes referentes, para consolidar alternativas auténticas, validadas y confiables desde el análisis crítico. Así, es posible superar ideas, modelos y propuestas cerradas, aparentemente incompatibles con otras. No se trata de mezclar acríticamente, por imposición, mitos, opiniones o experiencias, sino de construir propuestas diversas desde la reflexión rigurosa que otorga el conocimiento y la investigación.

Retornando a la bioética, esta ha desarrollado cuatro modelos educativos que se inspiran en la ética de la vida, desde los nuevos conocimientos de las ciencias y las humanidades, los cuales han permitido la comprensión del ser humano como parte de la vida, de la naturaleza y de la sociedad: doctrinal, liberal deliberativo e hipercrítico. En su conexión epistémico-pedagógica, estos modelos tienen en común la reflexividad en la acción del ser humano y el reconocimiento de la ética de la vida. Pero su conexión se explica en la relación que existe entre ellos también por su diferencia y los aspectos histórico-genéticos de su surgimiento. 
El doctrinal es un modelo tradicional, fundamentado en normas, desde la ética de la verdad; para la educación en valores, se trata del modelo de formación de hábitos virtuosos o de virtudes. El liberal, por su parte, se basa en los procesos morales autónomos resultados de los contratos entre los sujetos que participan en la solución del problema y en la toma de decisiones. Para este modelo los valores son del sujeto y por tanto relativos, subjetivos, de modo que se limita a exponer posturas y valorarlas; desde los modelos de educación en valores, este es el modelo clarificador. Por su parte, el modelo deliberativo, consistente en lograr una ética discursiva de comprensión intersubjetiva, se despliega de lo singular a lo universal, del simple diálogo a la generalización, utilizando la reflexión y la argumentación para la acción; se compara con el modelo de socialización de la educación en valores. Por último, el modelo hipercrítico, que considera la imposibilidad de acuerdos en la sociedad, no tiene una representación en los modelos de educación en valores, pues niega la posibilidad de generalización educativa.

La pregunta es ¿¿cuál de estos modelos es válido o más eficaz en la formación integral y la formación de valores? Responder esta interrogante solo es posible si se tiene en cuenta el contexto particular de que se trate, pues de esta manera se pueden establecer las estrategias apropiadas, para lo cual quizá se requiera la conjugación y complementariedad de estos modelos. En este sentido, dependiendo de las particularidades del contexto, se pueden tomar elementos de uno y de otro modelo para construir el que corresponda a sus necesidades específicas.

Otra expresión del eclecticismo reflexivo en las ciencias sociales está en la investigación y sus metodologías. Al respecto, Cronbach (1982) destacó que una de las estrategias en la realización de investigación social es el eclecticismo, que se manifiesta en la combinación de paradigmas (mixtura), de tipos de investigación, de métodos y técnicas, que depende de la reflexividad de los análisis del contexto del objeto de estudio, y que se concreta a través del pensamiento crítico del investigador y el uso de las diferentes fuentes de conocimiento.

La educación en valores se encuentra en un "agujero negro" del que parece no poder salir. Por una parte, esto se debe a la permanencia de valores 
anclados en lo tradicional, los cuales entran en tensión con los cambios en las nuevas generaciones. Por otra, a confrontaciones educativas y pedagógicas entre dos paradigmas curriculares: "crítico y estandarizado". El primero está asociado a la pedagogía crítica y el segundo a los estándares, las competencias, la eficacia y los resultados. Ambas perspectivas se hallan en un antípoda de enfrentamiento, lo cual impide la mediación y la complementariedad entre los aspectos que aparentemente se contraponen. Esto es corolario y secuela de la incomprensión del proceso histórico-evolutivo de las ideas pedagógicas y educativas en cada contexto, que destaca la diferencia y no la identidad, expresión de la limitación de la reflexividad y la dialéctica en la educación.

\section{Reflexividad pedagógica}

Es así que la unidad del conocimiento y el eclecticismo reflexivo en la pedagogía se constituyen en perspectivas teóricas que trascienden la formalidad de los modelos establecidos, al considerar la relación entre referentes que consolidan propuestas de formación auténticas, desde la investigación de los contextos y la delimitación del necesario enfoque educativo, considerado como aquella impronta que busca justificar las particularidades de los elementos educativos de cada escenario formativo. Al retomar la formación en valores profesionales, en el contexto militar se hace necesaria una fundamentación epistémico-pedagógica que se base en la reflexividad sobre la relación genética e histórica entre el conductismo y el constructivismo, que permita pensar y construir un modelo educativo propio, desde la mixtura de sus aspectos comunes y complementarios que estas ideas brindan a la formación integral del profesional.

El eclecticismo reflexivo llevado a la educación como reflexividad pedagógica (rasgos del giro epistémico en las ciencias sociales actuales) permite fundamentar nuevas propuestas pedagógicas, que solucionen las tensiones existentes en la formación militar integral entre el conductismo y el constructivismo pedagógicos, y desde allí construir propuestas teóricas y prácticas que consoliden los modelos educativos de manera auténtica y apropiada (Perilla, 2018). 
Este escrito es, en sí mismo, una reflexión crítica sobre el concepto de reflexividad pedagógica, referido a las diferentes maneras en que se interpreta y utiliza. Por una parte, las posiciones hipercríticas y dogmáticas hacia la racionalidad científica, que niegan la ciencia y el método científico en general, así como su aplicación a las ciencias sociales y, por consiguiente, a la educación. Por otra, la que se comparte, que consiste en que a través de este concepto se retoma el lugar de la crítica como valoración racional e interpretativa con un sentido ético, al reconocer los cambios epistémicos y metodológicos producidos en las ciencias sociales como parte de su desarrollo, siempre y cuando no se abandonen elementos que la identifican como tal en el marco de sus diferencias, como el método; la objetividad en relación con la subjetividad; la coherencia lógica y la sistematización del proceso de creación de conocimiento; el acercamiento a la realidad como contexto específico de estudio natural, cultural y social; la incorporación de la dialéctica entre lo universal, particular y singular, que permite el diálogo entre lo general de la teoría, lo particular del contexto de estudio y lo singular asociado al problema de investigación y reflexión; la subjetividad, no como subjetivismo, sino como reconocimiento del sujeto, de la individualidad, que realiza la reflexión crítica desde la historia, la epistemología y el contexto, para evitar la especulación, y del interpretativismo asociado al relativismo, a la "visión de túnel" que produce la disciplinariedad.

Específicamente, la reflexividad pedagógica es un sistema de conocimientos resultado de procesos históricos, dependientes de sus propios avances en diferentes momentos sociales e históricos, como producto de la investigación, donde el valor de la crítica en relación con la cooperación permite el intercambio a través de la socialización, la divulgación y la aplicación. En esta propuesta, la reflexividad pedagógica se halla en la flexibilidad metodológica, que requiere la actitud crítica constante respecto a las decisiones que se van adoptando para salvaguardar la rigurosidad y la congruencia metodológica y de contenido, así como la credibilidad de los resultados. La reflexividad pedagógica consiste en un análisis crítico permanente del investigador y su equipo en torno a la experiencia del proceso durante su ejecución. Es así que las decisiones metodológicas no dependen de modelos y costumbres del investigador, sino del contexto en que se realiza la investigación. 
A manera de síntesis, el reconocimiento de la reflexividad crítica en esta investigación no se suma a los enfoques cerrados devenidos de las interpretaciones posmodernistas, sino que apuesta por una epistemología de la integración del conocimiento y de la comprensión de la naturaleza humana, la cual se aparta de las comprensiones tradicionales de la ciencia y la investigación, así como de la aceptación acrítica de las corrientes relativistas actuales, que niegan la ciencia. Asimismo, reconoce la limitación de la desactualización del conocimiento científico, profesional y pedagógico; niega el pragmatismo-inmediatista que impide pensar responsablemente y no sabe cooperar y trabajar en equipo.

Es lamentable que la gran mayoría de los humanos no seamos conscientes del significado de la ciencia y la tecnología en nuestras vidas; de la responsabilidad social que tenemos con los conocimientos; del compromiso para que "educación y ciencia para todos" sea una realidad; de cómo la "ciencia debe estar al servicio de todos"; de cómo enseńar mejor a los nińos y jóvenes la ciencia en favor del bienestar humano; de cómo promover en los educandos el "amor" por la ciencia y la profesión científica; de cómo evitar la globalización de las ignorancias; de cómo enfrentar a las falsas ciencias y el resurgimiento del oscurantismo. (Wasserman, 2018b)

En su libro, Cómo tener siempre la razón, al representar al posmodernismo como corriente que reniega de la ciencia como parte de la cultura humana, Wasserman (2018a) señala:

Luego llegó el posmodernismo de izquierda con su relativismo moral. Resultaba entonces que todo valía si las circunstancias así lo exigían y que yo era psicorrígido [...]. El relativismo moral se extendió. La creencia de que el progreso era posible se volvió políticamente incorrecta y las costumbres ancestrales tomaron su lugar predominante. Yo era un joven progresista porque cría en la ciencia, en la igualdad, en la dignidad humana, en la independencia intelectual y en el progreso, y rechazaba las verdades reveladas y los dogmas. Hoy he sido notificado de que, pensando exactamente lo mismo, soy viejo y reaccionario. (pp. 41-42)

También destaca que algunas "verdades" se establecen y son aceptadas, pero son fuentes de ignorancia debido a la ausencia de conocimiento que causa la certeza, la autoridad en el conocimiento y los mitos. A lo que se refiere Wasserman es a la tendencia actual de rechazar aquellos valores defendidos 
en la Modernidad, en especial el predominio de la racionalidad en todas las esferas de la vida. Este punto de vista reconocido como posmoderno se aísla de los hechos, del continuum de la vida y de la cultura, y resalta las ideas e interpretaciones del sujeto como observador. Así, la certeza de un hecho es una verdad que se interpreta relativamente de acuerdo con el contexto, para lo cual se produce un cambio en el lenguaje que impide la identificación de lo "nuevo" con lo "viejo". En su posición más extrema, conduce a negar la ciencia, las ideologías y la historia, identificándolas con metarrelatos. A saber, no se reconoce una posición dialéctica de desarrollo, sino una ruptura crítica excluyente.

Sin pretender en este escrito profundizar acerca de la actitud de rechazo a ultranza del pasado que tienen algunas personas, no se puede dejar de afirmar que lo que somos hoy, bueno o malo, es resultado de la creación humana expresada en un continuum histórico y cultural. En este sentido, es sustancial hacer referencia a la negación de la negación, como parte del proceso dialéctico del desarrollo humano y social. La dialéctica, estudiada por filósofos como Heráclito, Aristóteles y Hegel, ha sido un conocimiento en constante reinterpretación en la filosofía hasta la actualidad y ocupa un importante espacio exegético respecto a los viejos problemas aún en debate, a la comprensión de los textos clásicos y al análisis de nuevos problemas de la naturaleza, la sociedad y la esencia humana.

Esto ha significado la continuidad de este conocimiento hasta la actualidad en Heidegger, por su aporte a la hermenéutica; en la contribución de Wittgenstein a la filosofía; en la aparición de la denominada filosofía del lenguaje, de la Escuela de Oxford; en la crítica de la razón instrumental en la Escuela de Frankfurt y en la subsecuente búsqueda de un concepto de racionalidad en la teoría de la acción comunicativa de Habermas, entre otras. También se desarrolló por otros caminos filosóficos desde Feuerbach, Engels y Marx, quienes contribuyeron a su desarrollo (Covarrubias, 2001).

La dialéctica es el método que permite establecer la relación e interdependencia de los fenómenos, acontecimientos y hechos. Una de sus leyes fundamentales fue formulada por primera vez en el sistema idealista de Hegel, la ley de la negación de la negación, que fundamenta el carácter progresivo del desarrollo, la sucesión, el nexo de lo nuevo con lo viejo, que tiene un significado 
opuesto a lo que es la negación como rechazo de lo anterior. Por el contrario, reconoce el proceso constante de renovación de lo viejo por lo nuevo, y del surgimiento de este último desde el saber tomar lo mejor de la cultura anterior, lo cual, sin lugar a dudas, se conecta con la capacidad de reflexión crítica en la acción de los sujetos, basada en el conocimiento de la historia.

Toda cultura científica debe comenzar por una catarsis intelectual y afectiva. Queda luego la tarea más difícil: poner la cultura científica en estado de movilización permanente, reemplazar el saber cerrado y estático por un conocimiento abierto y dinámico, dialectizar todas las variables experimentales, dar finalmente a la razón motivos para evolucionar. (Bachelard, 1987, p. 21)

En la actualidad, la pedagogía ha dejado de ser objeto de discusión y su debate como sistema de conocimientos se ha quedado limitado a las disciplinas y las didácticas, al saber, saber hacer y sus prácticas. De esta manera, se ha abandonado el sentido y el significado de la dialéctica como un sistema de conocimientos histórico, en proceso, tensión y, por tanto, en desarrollo. Sin embargo, es un sistema de conocimientos de larga data en la historia de la humanidad, que se ha transformado desde y para la cultura a través de la educación.

Como consecuencia, el carácter empírico de su tratamiento, en busca de la innovación y del cambio, no es acompañado por la investigación educativa desde el conocimiento pedagógico riguroso, histórico y epistemológico, para desde allí poder hacer propuestas de cambio fundamentadas. En ocasiones, muchos proyectos de innovación educativa se basan en un pobre argumento teórico y solo en la experiencia práctica y sus dificultades, lo cual evidencia que se confunde la investigación pedagógica con las soluciones prácticas de los procesos de enseñanza, aprendizaje, gestión y políticas educativas, las cuales se centran en la repetición de modelos con pobre novedad, o en la crítica de los existentes. Por ello, para el caso que se investiga, pensar en un modelo pedagógico particular requiere de la profundidad necesaria del conocimiento pedagógico, de tal manera que permita representar y contribuir al contexto de que se trate.

Al respecto, Tezano (2016), al referirse a la acción reflexiva del maestro en su práctica educativa para construir saber pedagógico, reconoce dos dimen- 
siones posibles de la reflexión pedagógica: "La reflexión como actividad mental-psicológica del ser humano" y la "reflexión entendida como praxis social". Sobre la primera destaca que se refiere al "proceso reflexivo que se produce cuando se articulan las operaciones mentales de representaciones, análisis, síntesis, relación, proposición, interpretación [...] que están potencialmente en el desarrollo cognitivo de los seres humanos". Por otra parte, indica que "la reflexión en su condición de praxis social implica el reconocimiento de su carácter colectivo, que reclama espacios democráticos, fundados en el respeto, para encuadrar el intercambio racional de ideas" (Tezano, 2016, pp. 11-12).

Esta concepción es limitada por las tendencias actuales posmodernas que rechazan la ciencia y su método, así como la historia en general, lo cual relativiza el debate y permite toda reflexión no fundamentada, que se queda en la opinión, la creencia y la experiencia.

Así, lo que se ha expresado hasta este punto evidencia la necesidad de adentrarse en la historia y la epistemología de la pedagogía para reflexionar, con base en las ideas y prácticas pedagógicas pasadas y en construcción permanente, diversos aspectos que han sido tratados anteriormente, tales como: el lugar del sujeto, la investigación, la integración de los conocimientos, entre otros. Solo a través de la reflexividad del continuum pedagógico se puede comprender la relación de las ideas pedagógicas en sus contextos de surgimiento y en la actualidad.

Adentrase en la epistemología no significa solamente responder a las preguntas tradicionales acerca de qué es el conocimiento, cómo se construye y cuál es su valor en general, sino también analizar las razones que argumentan estos interrogantes en los conocimientos particulares, sus contextos históricos, sus cambios, sus vínculos y polémicas. Del mismo modo, tener en cuenta la mirada actual de su evolución para identificar sus manifestaciones en la teoría y la práctica.

$\mathrm{Al}$ respecto, Bedoya (2018) destaca que hay que cuestionar no solo el paradigma, el modelo, el esquema, la representación abstracta de lo estudiado, sino también la forma de pensar, de aceptarlo sin reflexión con conocimientos (p. 108). Esto significa afirmar que hace falta desarrollar la capacidad del que 
investiga y educa, para conformar un conocimiento profundo de la pedagogía y de su historia, así como del contexto en que se halla para construir científicamente el modelo ideal y aplicarlo en la práctica, desde los nuevos conocimientos que avanzan sobre cómo pensamos, cómo aprendemos, cómo nos comportamos. Este es, precisamente, el modelo basado en la reflexividad pedagógica y la crítica.

Negar la necesidad de un paradigma o un modelo es una contradicción en sí misma, pues incluso si se separa de la diferencia y se decide en un solo camino, esto también se convierte de hecho en un modelo, que podría llamarse "el modelo del no modelo". Antes bien, lo que sería necesario es "el modelo del contexto", lo que permitiría la existencia de muchos modelos, fundamentados en el continuum de los sistemas de conocimientos pedagógicos, su génesis e historia.

Esto no significa rechazar los modelos, la ciencia, los conceptos, el método científico, el rigor de la coherencia ni los valores éticos que los acompañan en una reflexión crítico-pedagógica, la cual pasa por los sujetos implicados en la educación desde su contexto real y sus relaciones, que consiste en la necesaria introspección individual, colectiva e institucional. Por el contrario, significa pensar, investigar e innovar para impedir los traslados acríticos de modelos nacidos de otros contextos, que solo quedan en declaraciones y afirmaciones elegantes, pero copiadas, que no conducen a realizaciones pedagógicas para el mejoramiento y el cambio; en los que se ignoran y nunca se les da interés a los cuestionamientos que hacen de ellos los sujetos de la educación, sino que permanecen en el tiempo, casi como una identidad de la institución educativa, construidos desde ideales y buenas intenciones, pero no desde las necesidades pedagógicas y educativas. Al respecto, Bedoya (2018) asevera:

Los métodos que han integrado corrientes de pensamiento educativo se conocen a través de la obra de pedagogos del realismo naturalista, Comenio, Pestalozzi, entre otros, hasta los representantes de los métodos activos de Montessori, Decroly, entre otros, los cuales han sentado bases y elaborados fundamentos para sustentar el valor teórico de la pedagogía, según Piaget, como ciencia. (p. viii)

El cambio de las relaciones entre las ideas pedagógicas y educativas como resultado de los avances culturales es permanente, es un continuum que mani- 
fiesta la dialéctica de la negación de la negación, una ley epistémica general que enlaza el cambio como un proceso necesario en la evolución del conocimiento y de las ideas que nacen de la polémica y los requerimientos de la sociedad. Sin embargo, como afirma Bedoya (2018), no se debe

pretender el cambio por el cambio, [...] sino porque no se deben mantener prácticas obsoletas [...]. La actitud epistemológica de cambio debe ser precedida por la reflexión y autorreflexión de que no solo hay otras formas [...], sino porque comprendemos que como estamos procediendo actualmente estamos inhibiendo, reprimiendo y hasta atentando con las auténticas formas de acceder, investigar y producir conocimiento científico. (p. 6)

En este sentido, se debe reconocer que indagar en las relaciones históricas y genéticas del continuum del conocimiento pedagógico permite comprender y proponer nuevas ideas generales y contextuales, construir modelos generales y específicos.

Si se supone que una ciencia es o corresponde a una representación tecnológica o a la reducción didáctica que de ella se hace cuando se la enseńa, entonces son explicables las actitudes que hacia ella encontramos por lo general en el docente universitario. Hay que comenzar asumiendo una crítica de esta actitud hacia la ciencia y por lo tanto hacia la investigación que está tan institucionalizada aún hoy en día, a pesar del enorme desarrollo tecnológico —o tal vez debido precisamente a este- . Es decir, antes de exigir el cambio del modelo pedagógico, antes de pretender articular la investigación en el proceso pedagógico, antes de toda reforma curricular, hay que analizar estos supuestos con respecto a la ciencia y a su enseñanza. Es necesario iniciar una interpretación desde la epistemología y la historia de las ciencias con respecto a la forma como se representa, se hace y se enseña ciencia. (Bedoya, 2018, p. 10)

Llegados a este punto, se puede afirmar que la reflexividad es parte intrínseca de la educación y sus procesos pedagógicos de enseñanza y aprendizaje, de ahí que la cultura sea el resultado de esta actividad humana de crear y, desde la crítica, incorporar al presente lo valioso del pasado. Como se ha expuesto anteriormente, la dialéctica denomina a este proceso "negación de la negación", es saber seleccionar lo mejor y darle continuidad en la construcción del futuro. Dado que el continuum de la cultura ocurre en la sociedad a partir de la reflexividad humana, la reflexividad se produce necesariamente en el contexto cultural. 
Para destacar esta noción, a continuación, se presentan textualmente los argumentos de García (2008), profesor de Psicología Cognitiva, Psicolingüística, Neuropsicología y Neurociencia de la Universidad Complutense de Madrid, referente a esta capacidad humana:

La capacidad de aprender de los organismos es mucho más generalizada que la capacidad de enseñar. Mientras que todos los animales aprenden, muy pocos son los que enseñan. Enseñar es una de las capacidades más específicas y especiales de la especie humana. Gracias a la enseñanza de los diversos sistemas simbólicos (como el lenguaje, la escritura, los números, los mapas, la música, las leyes, las normas, etc.), nuestro cerebro puede incorporar en unos pocos ańos de la vida personal, miles de ańos de experiencia y conocimientos de la historia de la humanidad, posibilitando la educación y transmisión de cultura. (p. 70)

Ahora bien, la reflexividad es un término que se utiliza en educación, de manera frecuente, sin precisión categorial. En ocasiones se confunde con pensamiento crítico, con análisis, y se relaciona solo a la subjetividad interpretativa de acontecimientos, de manera que se limita a procesos de las ciencias sociales y sus desarrollos. Sin embargo, según García (2008), la reflexividad está presente en toda la construcción cultural a través de la actividad cerebral necesaria para desarrollar el conocimiento. Es un proceso permanente del pensamiento y el hacer del ser humano en relación con su entorno. Su carácter universal la constituye en una categoría epistémica, que explica cómo se produce el conocimiento humano y la cultura como proceso, lo cual permite comprender la evolución como tendencia del desarrollo humano, con sus altas y bajas.

Particularmente, en la educación la reflexividad pedagógica conduce a establecer, por una parte, el continuum entre las relaciones epistémicas de las ideas pedagógicas — que han surgido en contextos sociales específicos- y el resultado de los avances de estos conocimientos, y, por otra, los vínculos entre los diferentes sistemas de conocimientos y sus manifestaciones en los diferentes contextos en que se dan.

Precisamente respecto a esta interrelación de conocimientos, Vera y Palma (2017) afirman en su libro Enseñar a aprender: Pedagogía basada en la reflexividad que la educación constituye un conjunto dinámico de actividades, 
relaciones personales, recursos, conocimientos y formas de organización, entre otros componentes, que interactúan entre sí, lo cual significa que si se cambia una de ellas, las otras también se transforman en alguna medida. Esto implica que las teorías, metodologías, didácticas, prácticas educativas y culturas institucionales, al actuar entre sí como conjunto, se influyen unas en otras. Por tanto, cada componente del conjunto del sistema es portador de una racionalidad determinada por la pedagogía y su relación con otros conocimientos, según el momento histórico cultural. Esto conduce a pensar que el modelo pedagógico ideal, teórico, y su práctica son eficaces en la medida en que exista una relación coherente entre ellos, que sea dialéctica, esto es, que sea reflexiva desde el pasado y el presente hacia la construcción de la educación del futuro, enmarcada en la comprensión del contexto específico en que se piensa y actúa.

La reflexividad pedagógica no solo contiene los sistemas de conocimientos de los seres humanos reflexivos para la toma de decisiones y acciones coherentes dependiente de la cultura aprendida, sino que también es la esencia del pensamiento y la expresión humana, de la naturaleza biológico-psicológica. Se produce en los procesos de aprendizaje, en el sistema cognitivo cerebral, e implica no solo lo racional, sino también lo emocional, así como la memoria, la experiencia, la imaginación, el carácter, entre otros.

Para sintetizar lo que se ha expresado anteriormente, se puede afirmar que la reflexividad en la educación es un concepto que permite vincular los diferentes enfoques pedagógicos al contexto educativo y a las particularidades de la profesión que se forma, de manera que hace posible fundamentar didácticas de aprendizaje que sean acordes con ellos. Asimismo, la reflexividad pedagógica permite argumentar y construir puentes de enlace respecto a la epistemología, las metodologías y las estrategias didácticas que se deben seguir; es decir, es una herramienta para pensar el modelo ideal pedagógico de la formación específica desde los contextos particulares, como es el caso de la formación del profesional objeto de estudio.

Asimismo, la reflexividad pedagógica es la acción humana que permite acuerdos entre las personas que participan en los procesos educativos. A través de la interiorización, exteriorización y socialización de conocimientos implícitos y explícitos que tiene lugar en la participación y comunicación entre las 
personas que intervienen en el proceso educativo, la reflexividad pedagógica vehiculiza los acuerdos conceptuales, referenciales y operativos en ámbitos organizacionales-culturales, científicos-profesionales y pedagógicos-didácticos, relacionados con los posicionamientos experienciales, epistémicos, profesionales y generacionales. De esta manera, hace posible llegar a principios, valores, lenguaje común, trabajo en equipo, colaboración, cooperación, entre otros, para una práctica comprendida y compartida.

Ahora bien, es importante agregar que la reflexividad pedagógica está relacionada con el cerebro, con sus características internas y con las expresiones culturales que este recibe de la educación desde la sociedad. Por lo tanto, para comprenderla también es necesario tener en cuenta los fundamentos de los procesos cognitivos que las neurociencias han desarrollado, tales como el reconocimiento del papel que tiene la imitación en el aprendizaje debido al descubrimiento de las neuronas especulares, células especializadas en el comportamiento, y los estudios de la teoría de la mente.

Rizzolatti (2005), destacado neurocientífico, muestra en sus investigaciones que las neuronas que denomina neuronas espejo se activan tanto al ejecutar una acción, como al observar la ejecución de una acción. En este último caso, la neurona reproduce la misma actividad neural que la acción que se observa, pero sin realizarla de manera externa (corporal), sino como una representación mental de la acción, de modo que es una respuesta neuronal del cerebro. Este neurocientífico adopta desde la definición de imitación de Thorndike ${ }^{1}$, quien desarrolló el conductismo como teoría del aprendizaje, al señalar que existe un vínculo neural entre el estímulo y la respuesta, lo cual produce un aprendizaje y una manifestación en la conducta. Si bien en este escrito no se busca desarrollar la polémica existente en este campo de la psicología cognitiva, sino establecer las conexiones en el avance de la ciencia, cabe señalar que investigadores como Narciandi y Marín (2009) destacan otras miradas sobre la imitación:

1 Edward Lee Thorndike, psicólogo y pedagogo estadounidense, antecesor de la psicología conductista. Entre sus principales contribuciones están el aprendizaje por ensayo-error, la ley del efecto y la teoría del conexionismo. 
En vez de entender la imitación como una capacidad psicológica yuxtapuesta a otras, que consiste en la reproducción completa y rápida de la actividad del modelo, el punto de vista constructivista la entiende como una función psicológica, sometida a una génesis y contextualizada ontogenéticamente. (p. 1)

La teoría de la mente, concepto ya manejado en la etología, la filosofía y la psicología, comienza a ser de interés en las ciencias cognitivas en los años ochenta y noventa en la neuropsicología y la neurociencia cognitiva social. La teoría de la mente reconoce la habilidad cerebral que permite interpretar y predecir el comportamiento de otros, las intenciones, los sentimientos y los intereses, cuestión que fundamenta las conductas de los seres humanos ante situaciones determinadas. Entre los investigadores reconocidos están: David Premack (uno de sus fundadores), Uta Frith, Joseph Perner, Simon BaronCohen, Ángel Riviére, Daniel Dennett, Jerry Fodor y Annette Karmiloff.

Ambos estudios contribuyen a entender mejor la conducta desde la biología humana en relación con el contexto de vida, así como el lugar que tiene la capacidad reflexiva en la mente humana. Estos conocimientos contribuyen a comprender en qué consiste la reflexividad pedagógica, no solo como un fundamento epistémico, que contempla la unidad de lo diferente, sino también como una reacción y método del aprendizaje de los seres humanos. Consecuentemente, la reflexividad pedagógica es tanto fundamento epistémico para la estructuración pedagógica desde la mirada de los contextos, como método para aprender socialmente.

Es así que son diferentes los terrenos en que se requiere la reflexividad en la educación. Para González Gil (2009), la investigación cualitativa requiere de flexibilidad o actitud crítica constante en aquellas decisiones metodológicas que se van adoptando para salvaguardar la rigurosidad y la congruencia metodológica, así como la credibilidad de los resultados. La autora destaca la comunicación entre el investigador y el desarrollo de la investigación, pues mediante sus acciones incide en el proceso de investigación y sus resultados, y desde allí también se produce un cambio en la comprensión de la problemática estudiada, desde su introspección basada en sus conocimientos teóricos, experienciales y preceptivos. La reflexividad implica una continua conversación con uno mismo, con lo que piensa y hace, es una actitud y un comportamiento. 
Respecto al proceso de enseñanza-aprendizaje y la formación de personas reflexivas, Vázquez (2017) apuesta a que se deben crear las condiciones para promover la reflexión en las aulas, utilizando didácticas significativas y problemáticas que ayuden a pensar y desde allí a hacer acciones creativas. La formación de profesionales reflexivos es una propuesta de finales del siglo XX, relacionada con la formación integral. Entre los principales iniciadores y exponentes de esta corriente están Lawrence Stenhouse y Edward Hallett Carr en Inglaterra, John Dewey en Estados Unidos, Stephen Kemmis en Australia, José Gimeno Sacristán y Rafael Porlán en España, entre otros.

Por su parte, la noción de práctica reflexiva fue introducida por Donald Schön (1998) a través del análisis del concepto de profesional reflexivo, que consiste en el desarrollo de la capacidad reflexiva para poder acceder al conocimiento de las complejas relaciones entre pensamiento y acción. Referente al maestro, distingue reflexión en la acción y reflexión sobre la acción, desde las cuales argumenta que el auténtico profesional es aquel que da soluciones apropiadas a los problemas desde el conocimiento.

Posteriormente, Domingo (2008) toma de Schön (1998) estos niveles de reflexión y los reconoce en aspectos como: reflexión sobre la práctica, reflexión en la práctica y reflexión para la práctica. Asimismo, destaca las categorías pedagógicas de formación reflexiva, competencia reflexiva, práctica reflexiva, pensamiento crítico y reflexivo, análisis reflexivo y análisis crítico. Según afirma la autora en su tesis doctoral, los rasgos de la práctica reflexiva del maestro se reconocen en el diálogo que establece entre los conocimientos científicos y la propia práctica; la enseñanza para el aprendizaje crítico-transformador; el dominio de la complejidad educativa; la innovación educativa y la investigación acción como posible mejora. Además, señala que el conocimiento teórico o académico pasa a ser considerado instrumento de los procesos de reflexión, teniendo en cuenta que este carácter instrumental solo se produce cuando la teoría se integra de forma significativa, imbricándose en los esquemas de pensamiento más genéricos que son activados por el docente en su práctica.

Desde otra perspectiva, Vera y Palma (2017) consideran que la reflexividad en la práctica educativa también se halla en el campo de la gestión de la educación, específicamente en los cambios asociados a la cultura institu- 
cional desde la mirada reflexiva de los entornos externos. De acuerdo con estos autores, la presencia aún vigente de la administración escolar basada en enfoques tradicionales causa problemas no solo en la cultura institucional, sino también en las prácticas reflexivas que contribuyan al cambio. De ahí la importancia vital de la reorganización de la gestión educativa a partir de los postulados de la renovación administrativa y de la reflexividad crítica desde lo pedagógico y la articulación con el contexto social.

Es así que la implementación de la administración tradicional de corte empresarial vigente en las instituciones escolares impide su desarrollo porque limita el proceso reflexivo-investigativo para responder a las necesidades del contexto y la formación de los diversos actores presentes en ellas (maestros, familias, estudiantes, directivos, proveedores, comunidad circundante, etc.).

La gestión educativa no se debe guiar por modelos predeterminados, estandarizados o incluso devenidos de contextos ajenos a la educación. Se requiere de un cambio de percepción y de acción, donde los componentes instrumentales pasen a un segundo plano y la esencia de la gestión sea el ser humano, su motivación y participación, las relaciones, los conocimientos, los valores, entre otros aspectos que dan el contenido a los procesos educativos y forman parte de la reflexividad pedagógica.

En la investigación "Enfoques y tendencias epistemológicas y teóricas de la gestión en educación en Colombia desde mediados de los años noventa hasta la actualidad”, de la Universidad Pedagógica Nacional (2015), se evidencia que la política pública de calidad en educación desconoce la tendencia de corte humanista en la gestión educativa. Los enfoques que halló la investigación fueron el tradicional, semicrítico-sociohumanista y crítico-pedagógico (denominados así por los investigadores), entre los cuales se manifiesta la tensión de la transición. El primero, inscrito en la instrumentalidad y la mirada tradicional, normativa, en pro de la eficacia y la eficiencia de los resultados; el segundo, considerado un punto de reflexividad para el cambio, y el tercero, la aspiración e ideal en tensión permanente con lo instrumental (Arana et al., 2016, p. 118).

Otro ámbito educativo en el que debe estar presente la reflexividad pedagógica es el currículo y su diseño, que se puede estructurar desde diferentes concepciones, de manera que es común encontrar una diversidad de enfo- 
ques para las propuestas de formación. Algunos de estos centran su interés en los contenidos, otros en las habilidades y otros en las actitudes, los cuales se pueden conjugar, desde la perspectiva de la reflexividad pedagógica, para consolidar nuevos alcances del diseño curricular dependiendo de los contextos educativos.

Según Perilla (2018), las exigencias de un contexto provienen de manera conjunta y dinámica de diferentes actores concretos. Si además se tienen en cuenta los antecedentes, es posible comprender en qué punto fundamental se debe enfocar el diseńo curricular, lo cual evita caer en temas innecesarios y desconocer las características específicas que puedan fortalecer la implementación efectiva de la propuesta de formación que se pretenda realizar (Perilla, 2018, pp. 27-28).

Ahora bien, esta conjugación de elementos curriculares en el marco de procesos de investigación se puede hacer desde la perspectiva del eclecticismo reflexivo, el cual tiende a establecer propuestas auténticas para realidades específicas. La autenticidad se configura cuando los diseños curriculares no se centran en repetir las teorías o diseños realizados por otros, sino que al atender a las características de cada contexto formulan una propuesta pertinente para esa realidad. Si bien es una ardua tarea de investigación educativa, se pueden generar propuestas fundamentadas en procesos de validación rigurosos (Perilla, 2019).

Concretamente, el eclecticismo reflexivo como estrategia de diseño curricular parte de la realidad del contexto, es decir, de información proveniente de fuentes diversas, que al ser escuchadas en conjunto revelan cuáles son las exigencias del contexto que son útiles para elaborar el diseño curricular. No obstante, la información que se recibe de la realidad debe ser validada de manera reflexiva, lo cual permite articular elementos de forma auténtica y configurar el eclecticismo reflexivo (Posner, 2005). En este sentido, el eclecticismo reflexivo posibilita que el diseñador del currículo pueda interpretar su contexto desde diferentes fuentes de información, articulándolas de forma coherente, para dotar de pertinencia cada propuesta de formación específica e integrarlas. Esto implica que el proceso de diseño curricular deja de ser un ejercicio con respuestas exactas, para convertirse en una posibilidad de investigación y creación auténtica que no puede repetirse de manera idéntica en contextos diferentes (Gimeno, 2007). 
De esta manera, el eclecticismo reflexivo constituye una mirada epistémica para el diseño curricular que no solo trasciende la formalidad de las propuestas teóricas, sino que además atiende diferentes referentes para consolidar una mixtura que supere las copias creadas en contextos ajenos y dotar de pertinencia a aquello que se quiere lograr con sujetos específicos. No se trata de mezclar por mezclar, sino de construir propuestas desde la reflexividad pedagógica rigurosa que otorga la investigación.

\section{Relación histórico-genética entre el conductismo y el constructivismo pedagógicos}

Para los profesionales de la educación, adentrarse en el estudio de la pedagogía de la Modernidad como movimiento educativo significa hallar un caudal de conocimientos que permiten la reflexividad. Esto es posible gracias a que esta se caracteriza por la riqueza de un pensamiento y una práctica educativa centrada en el sujeto que aprende y en las relaciones humanas, lo cual aportó nuevas maneras de pensar y actuar en los procesos de enseñanza y aprendizaje respecto al educador, el estudiante, los métodos, las técnicas y la gestión de la institución educativa.

La pedagogía de la Modernidad rompe con los rígidos esquemas de la pedagogía tradicional e introduce cambios de mentalidad asociados a los contextos de mediados del siglo XIX. No obstante, su relevancia se destacó en el siglo XX y su influencia no ha desaparecido, pues muchos de sus principios continúan vigentes en la actualidad, a veces fusionados con las concepciones contemporáneas, que de hecho provienen de ella. De esa escuela tradicional en la que el estudiante fue un receptor pasivo, dócil, al que se debía proteger, se pasa gradualmente al estudiante sujeto protagonista, descubridor y agente de su propio aprendizaje.

Hoy los cambios educativos y culturales exigen pensar la pedagogía y la educación desde sus tradiciones, pero también desde los nuevos conocimientos científicos y tecnológicos, los cuales permiten nuevas experiencias y saberes resultados de las prácticas. $\mathrm{Al}$ mismo tiempo, hacen necesario pensar los paradigmas y sus enfoques deterministas en la enseńanza y la educación, que en 
ocasiones han alejado o rechazado la unidad del conocimiento y la integración de lo biológico-psicológico con lo social y lo cultural. Nuevos conocimientos que hoy se desarrollan para comprender más al ser humano, su naturaleza y a la sociedad que construye y vive.

Por lo anterior, cada vez más la pedagogía y las ciencias de la educación deben ser constituidas por las ciencias que también estudian al ser humano y los procesos de aprendizaje desde otras disciplinas, en especial al órgano que así lo permite, el cerebro, de manera que los educadores puedan reflexionar y proponer ideas pedagógicas que integren la neuroeducación, como ocurrió en la Modernidad con la psicología, la sociología y las tecnologías del momento.

Sin embargo, no solo se hace necesario que los educadores abreven nuevos conocimientos, sino que se incorporen a los llamados que las ciencias cognitivas y otras les hacen a las ciencias sociales y, en particular, a quienes les interesa saber cómo aprende el cerebro. De esta manera, es posible construir didácticas más acordes con los procesos de aprendizaje y tratar de responder a la pregunta de cómo enseñar al cerebro humano.

Tomar como punto de partida la reflexión acerca de las ideas pedagógicas de la Modernidad permite observar que estas no quedaron en el pasado, sino que continúan aportando a la evolución de la educación. Es decir, no se trata solo de un asunto histórico y epistemológico en el campo pedagógico, sino de su presencia en la educación actual, la cual se debe reconocer de manera reflexiva, activa, crítica y científica desde la investigación educativa y a través de equipos multidisciplinarios. Ese es el legado y el reto por seguir: retomar las características históricas y epistémicas de la pedagogía de la Modernidad, así como el método reflexivo desarrollado por nuestros antecesores en su momento, los cuales pensaron y actuaron, sobre los hombros de la ciencia, con procesos de enseńanza para el aprendizaje y el desarrollo del ser humano.

\section{Continuum y relaciones entre las ideas pedagógicas en la Modernidad}

Para relacionar lo anterior con lo que se expuso acerca del continuum de las ideas pedagógicas, es necesario analizar las características del contexto histórico en que estas surgieron. Asimismo, desde el estudio de sus crea- 
dores, hallar los conceptos y rasgos fundamentales compartidos que permiten resaltar la continuidad y la complementariedad de estas ideas, lo cual ayudaría a entender la relación entre la pedagogía conductista y constructivista en su génesis (figura 1).

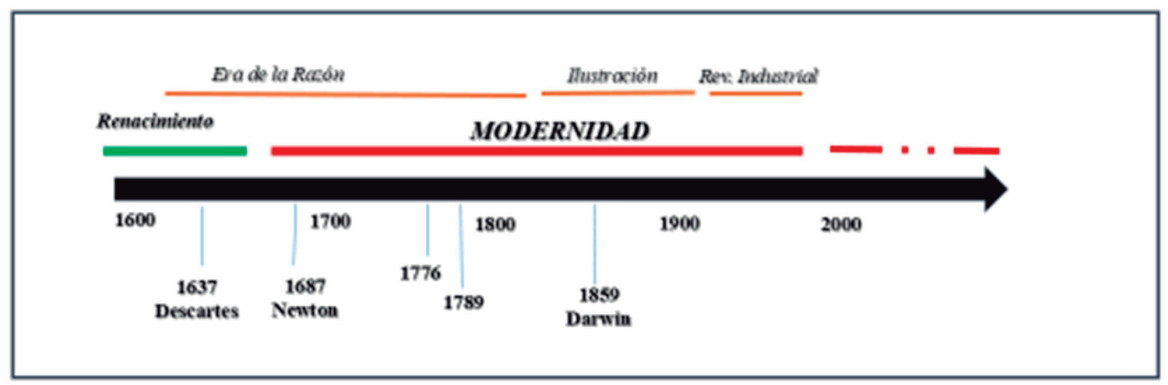

Figura 1. Evolución del contexto histórico de la Modernidad.

Fuente: Elaboración propia.

La Modernidad es un período de la humanidad en que se produce una reacción en contra de la filosofía medieval y la escolástica dominante en el continente europeo desde el siglo V d. C. hasta finales del XV d. C. Sus ideólogos más reconocidos fueron Descartes, los empiristas, los racionalistas, Kant y Hegel. Ellos destacan la utilidad de la razón para dar respuestas a los problemas del conocimiento y la sociedad. En 1784, el escrito de Kant titulado Respuesta a la pregunta ¿Qué es la Ilustración? muestra el proyecto de la Modernidad, concepción del mundo en que se desconfía de todo aquello que no puede ser pensado o racionalizado, del conocimiento a través de los sentidos, las emociones y de las diferentes formas de aprehensión que no posean la característica de la ciencia descrita por Descartes de ser ideas claras y distintas, o de Kant de ser juicios necesarios y universales. En la actualidad, sus principios epistémicos y educativos han cambiado en cuanto a la comprensión de la ciencia y la educación, pues rompieron la separación entre la razón y la emoción como partes integrantes e inseparables del ser humano.

Entre los pedagogos destacados de este período histórico están Jan Amos Comenio y Juan Jacobo Rousseau. Asimismo, se reconoce a Johann Pestalozzi, Johann Herbart, Jean Piaget, María Montessori, Friedrich Fröbel y Robert Gagné, entre otros. Todos ellos desarrollaron ideas y construyeron pedagogías 
con un sesgo racionalista característico de la Modernidad. Sin embargo, cabe preguntarse qué prevalece de ellos en las pedagogías contemporáneas, cuáles son sus aportes a la educación y cuáles de sus planteamientos no se han alcanzado y continúan siendo un ideal de la educación.

Desde la mirada histórico-genética seguida en esta investigación, se observa que las ideas pedagógicas que se destacan desde la Modernidad hasta mediados del siglo XX se apoyan en los avances culturales, sociales y científicos, y en su mayoría son desarrolladas por profesionales de otros campos del conocimiento. El propósito de indagar en ellas es destacar los aspectos comunes que tienen sus propuestas y, de esta manera, transferirlos a la actualidad y compararlos con las nuevas ideas pedagógicas actuales. En el caso específico de esta investigación, se hace referencia al conductismo y el constructivismo pedagógicos.

La polémica en la educación a partir del desarrollo de la ciencia a finales del siglo XIX y comienzos del XX tiene dos grandes manifestaciones fundamentales en lo epistemológico: el idealismo absoluto y el positivismo. En ambos domina la idea de la realidad única que se desarrolla y progresa por el espíritu o la razón, o por la relación de ambos. Esta polémica se inicia con las respuestas corrientes en contra del positivismo como representación cerrada de la ciencia, las cuales abogan por una "recuperación del sujeto" e impulsan a destacar las diferencias y las emociones, lo cual conduce al relativismo y la negación de la ciencia.

Este debate se produce fundamentalmente en las ciencias sociales y, por lo tanto, impacta a la educación, lo cual se evidencia en propuestas renovadoras y críticas al tradicionalismo que caracteriza al magistrocentrismo, tales como la pedagogía social y la pedagogía activa (Arana, 2018a). Acudir a la epistemología de ese período permite comprender las tensiones y tendencias del pensamiento pedagógico, las ideas que de allí surgen y los posicionamientos teóricos y las prácticas educativas.

Específicamente, las corrientes sobre el conocimiento que surgieron en este período son las siguientes: el racionalismo, filosofía que nació en el siglo XVII en Francia y en la que se destaca Descartes. Se centra en el reconocimiento de la razón como principal fuente para la adquisición de los conocimientos, destaca la validez de lo universal y el método analítico basado en la razón. El 
denominado cartesianismo aisló en sus planteamientos al sujeto del objeto, a la razón de la emoción, entre otros aspectos. Así, la pedagogía racionalista fue un movimiento pedagógico y educativo inspirado en el denominado racionalismo pedagógico, que afianzaba la educación con base en la lógica y la razón. Como resultado, se desarrolló la secularización de la educación, se reconocieron las lenguas maternas y la matemática asume un lugar relevante en compañía de las ciencias naturales, fundamentalmente la física.

En respuesta a lo anterior, el irracionalismo se basa en la negación de la realidad y su posible conocimiento. Esta posición epistémica reconoce la especulación, el relativismo y la interpretación como aspectos fundamentales en la búsqueda del conocimiento. Sus principales representantes son Schopenhauer y Nietzsche. La incidencia que tuvo en la educación se evidencia en el rescate del ser humano a través del arte y en el retorno de la intuición e inducción desde la vida, lo cotidiano, la experiencia personal y el sentir individual, con lo cual se desecha la generalización de la ciencia y la posibilidad del conocimiento de la realidad.

Como una expresión del racionalismo, en las ciencias sociales se desarrolló el positivismo, una corriente epistémica que tiene como propósito utilizar los métodos y los resultados de las ciencias positivas. Además, exalta las ciencias experimentales y afirma que la ciencia es el único camino para garantizar el "progreso indefinido" del ser humano y de la sociedad. Su fundador fue Auguste Comte y se reconoce también a John Stuart Mill. Una de sus variantes fue el evolucionismo — proveniente de los estudios de la evolución y la teoría evolucionista de Charles Darwin-, que se centra en las conexiones que se producen entre las transformaciones de la vida como proceso de desarrollo. Su principal representante fue Herbert Spencer.

Los atributos y distintivos del positivismo están en el método de la observación, la inducción, la comparación, la clasificación y la generalización de los resultados, y la neutralidad de los análisis para evitar la interpretación sin fundamento objetivo. En la educación se acentúa en la enseñanza disciplinar de las ciencias positivas, entre ellas la física, la química, la biología, las matemáticas, la educación física, el estudio de la naturaleza y la educación para el trabajo desde lo técnico. Así aparece la escuela politécnica e industrial, pues el 
aprender haciendo es una de sus ideas pedagógicas, la cual está acompañada de la autonomía del estudiante y la crítica a la disciplina rígida y cerrada, basada en los castigos, que es sustituida por la razón y la comprensión.

En réplica a estas concepciones se erigieron otras corrientes epistémicas como mediación o desarrollos de estas y que también inciden en la educación. Entre ellas se encuentran la filosofía analítica, el neopositivismo y el neoempirismo, que tienen en común la crítica a la metafísica y el apoyo al lenguaje de la ciencia. Sus representantes principales son Bertrand Russell y Ludwig Wittgenstein.

También se debe mencionar la fenomenología, enfoque filosófico que destaca la conciencia y la intencionalidad. En la enseñanza, específicamente, se basa en la experiencia y el método inductivo basado en la descripción de los fenómenos, es decir, de lo que aparece en la conciencia. Su objeto de estudio son los hechos en el sujeto y entre sus representantes se encuentran Edmund Husserl, Nicolai Hartmann, Karl Theodor Jaspers y, en la teoría ética, Max Scheler. Por otra parte se encuentra el existencialismo, que reflexiona sobre los problemas que se le plantean al ser humano concreto, con un marcado enfoque individual. Entre sus representantes están Martin Heidegger, JeanPaul Sartre, Albert Camus y Maurice Merleau-Ponty.

Otras tendencias dan vuelta hacia el reconocimiento de la ciencia, como la filosofía de la acción. De ella se desprende la pedagogía de la acción como una corriente pedagógica de mayor influencia en la educación contemporánea, contraria a la pedagogía tradicional, pues se centra en la actividad. Además, se debe mencionar la filosofía de la ciencia, que entiende a la ciencia como actividad humana en sentido amplio, en su unidad y en su análisis crítico. Sus representantes son Karl Popper, Imre Lakatos y Paul Feyerabend (figura 2).

Lo anterior se presenta en la historia de la educación a través del enfrentamiento entre el humanismo y el realismo. En el Medioevo tenía prioridad la educación humanista; en el Renacimiento ambas coinciden; en la Modernidad, aunque la tendencia es el realismo de la ciencia, sin dudas al igual que en la contemporaneidad coinciden ambas, en un enfrentamiento que da lugar al reconocimiento cada vez mayor de la relación de una en otra a través de la unidad del conocimiento, de la vida y del ser humano, comprensión que lleva 


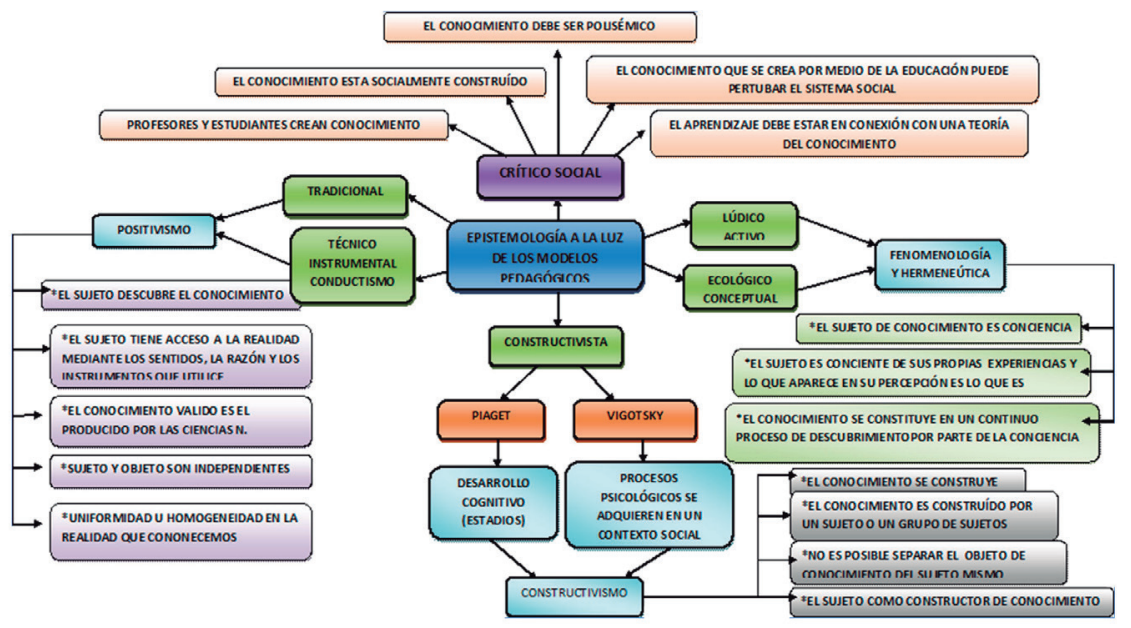

Figura 2. Esquema representativo de la epistemología y su efecto en la pedagogía y la educación.

Fuente: Elaboración propia.

a entender la relación entre lo objetivo y lo subjetivo, la razón y la emoción, las humanidades y la ciencia, que son reconocidas como partes de un todo.

Una expresión de la conexión que se va construyendo entre los diferentes enfoques se observa en la obra La didáctica magna, de Comenio, que de manera visionaria expresa ideas pedagógicas que interconectan y resumen las tendencias de la educación de la época, al tiempo que propone nuevas ideas. Entre estas se pueden destacar las siguientes: el principio de la organicidad del saber; el carácter disciplinario de la organización escolar de la llamada "escuela reloj”; la descripción del comportamiento del maestro ante los discípulos; la justificación del sentido social de la educación y las "escuelas de masas"; el reconocimiento del método natural, basado en la experiencia sensible, entre otros.

Se trata de aspectos de la escuela moderna y democrática desarrollada a finales del siglo XIX y mediados del XX. En este contexto, la pedagogía es pensada desde la idea de que la educación sirve para mejorar a la persona y a la sociedad a través de la normalización de un saber base para todos por igual, así como mediante un currículo cerrado que optimiza los procesos y los regula. Esta homogeneización de la educación comienza a ser cuestionada a mediados del siglo XX, luego de la Segunda Guerra Mundial, de modo que 
la educación es encaminada hacia la mejora individual a través, por un lado, del resurgimiento del individualismo planteado por el liberalismo y, por otro, de las ideas pedagógicas que se enmarcan en modelos político-sociales que delinean la formación.

A partir de estas corrientes de pensamiento surgen varias ideas pedagógicas como respuestas y propuestas educativas que contienen estas polémicas en sus diseños y modelajes. Con el apoyo de nuevos conocimientos sobre el ser humano y su proceso de aprendizaje, así como de nuevos saberes y medios de enseńanza, se cambia el rol del maestro y de la institución educativa, la cual deja de poseer la exclusividad del conocimiento.

Como consecuencia, la autonomía del aprendizaje que posibilitan las tecnologías de la comunicación y la información ponen en jaque al currículo homogéneo, esencia de la educación "disciplinaria" y "normalizada". Esto conduce a que sea necesaria la reflexión crítica como condición de la transformación creativa de la institución educativa, del maestro y de los procesos educativos, con lo cual se impide que los amplios y atrayentes recursos tecnológicos sustituyan al maestro o que este se convierta en un apéndice de las plataformas y los sistemas virtuales, en los que el diálogo y la mirada humana son sustituidos por íconos impersonales, se incrementa el gusto por el juego y no por la lectura ni la lógica de la razón humana.

La educación, como práctica social, se promueve como compleja y diversa, gracias a las demandas del contexto sociocultural y a las interpretaciones de la creciente y deslumbrante producción pedagógica que se ha venido desarrollando en los últimos tiempos. Con la pretensión de cambiar la escuela y el proceso de enseńanza-aprendizaje, y de reconstruir todas las prácticas pedagógicas, se dibujan de manera tenue, pero con energía, varias corrientes contemporáneas pedagógicas. Estas son consideradas por Contreras, Hernández, Puig, Rué, Trilla y Carbonell (1996) como campos, corrientes, discursos [...] que expresan, a nuestro entender, líneas de fuerza en el pensamiento y/o en la práctica educativa. (Suárez, 2000, p. 42)

\section{Vínculos y vigencia de las ideas pedagógicas del siglo XX}

Estas transformaciones son consecuencia de la reflexión crítica sobre la pedagogía y la educación, pero con nuevos elementos culturales. Así se evidencia al analizar desde un enfoque histórico algunas de las ideas pedagó- 
gicas que han surgido en el marco del siglo XX, centradas en el rechazo a la pedagogía tradicionalista, magistrocentrista, normativa, heterónoma y disciplinaria. Con el apoyo de nuevos conocimientos de la biología, la medicina, la psicología, la sociología y los avances tecnológicos de las comunicaciones, estas ideas permitieron pensar y proponer cambios dirigidos a centrar la atención en el ser humano, su desarrollo cognitivo y emocional, así como pensar en la integralidad de estos elementos sin negar el lugar de la razón, con el principio de que somos seres humanos emocionales que razonamos. Por consiguiente, en las nuevas ideas pedagógicas, construidas desde la consideración reflexiva de las anteriores, se observa la coincidencia y tendencia a pensar en la enseñanza del sujeto que aprende desde una visión integral de este, respecto a lo biológico-natural y lo social-cultural.

Al respecto es importante señalar que este escrito asume un posicionamiento histórico que se nutre del trabajo de varios autores. Por una parte, en lo que señala Jaime Carbonell (2000), en el prólogo a Cuadernos de pedagogías del siglo XX, donde señala: "Las ideas surgen a partir de reelaboraciones de otras anteriores. Es lo que sostiene Vygotski, el llamado Mozart de la psicología, cuando nos dice que la capacidad creativa consiste en construir lo nuevo a base de reconstruir lo viejo" (p. 5).

Del mismo libro, específicamente del escrito titulado "Los inventores de la educación y cómo nosotros la aprendemos" (Sacristán, 1995), se considera pertinente la cita de Ortega y Gasset en la presentación de su obra Ideas y creencias:

El defecto más grave del hombre es la ingratitud. Fundo esta clasificación en que, siendo la sustancia del hombre su historia, todo comportamiento antihistórico adquiere en él un carácter de suicidio. El ingrato olvida que la mayor parte de lo que tiene no es obra suya, sino que le vino regalado de otros, los cuales se esforzaron en crearlo y obtenerlo. Ahora bien, al olvidarlo desconoce radicalmente la verdadera condición de eso que tiene. (p. 13)

Asimismo, se acude a las ideas de educadores del siglo XX, quienes muestran el avance de la enseñanza desde los nuevos conocimientos de la ciencia del momento y que conducen a pensar la educación de manera reflexiva e histórica. El principio que condujo a esta reflexión de la investigación educativa 
es que el valor de las ideas y sus propuestas concretas no reside solo en lo que representaron en su momento, sino en su poder iluminador en el presente para enfrentar la incertidumbre de los nuevos retos educativos.

Acudir a la memoria es recuperar la cultura que antecede a las preocupaciones y problemas actuales, para desde allí hallar nuevas soluciones, colmadas de los recuerdos de hechos, ideas, sensaciones, relaciones entre conceptos y todo tipo de estímulos que ocurrieron en el pasado, ya sea de manera personal o como aprendizaje de acontecimientos significativos de nuestro entorno. Así, se asocian al recuerdo, que consiste en la restauración de lo pasado y conservado en ella. Recordar permite crear e innovar en el presente y proyectar hacia el futuro cambios que se consideran necesarios, para el caso, en la pedagogía y la educación. No obstante,

somos cautivos del presente, de una realidad de contornos lineales, cerrados y uniformes, delimitados por la inmediatez. Nuestra mirada se resiste a volver la vista atrás y a proyectarse libremente hacia el futuro. Demasiados corsés y demasiado pensamiento único, a pesar de tanta retórica en torno al pluralismo y la diversidad, los cuales, dicho sea de paso, permanecen algo aletargados, con escasa energía, sin alas para emprender el vuelo hacia horizontes lejanos. (Carbonell, 2000, p. 5)

Hay estudios actuales de la neurociencia que afirman que el recuerdo requiere del olvido, que es una función de la memoria, pero que se olvida aquello que no es significativo. Sería difícil pensar que, en la investigación educativa, las ideas pedagógicas del pasado se olviden, por no ser consideradas relevantes, pues en ellas están las fuentes de continuidad del conocimiento pedagógico, que como en cualquier otra ciencia permiten pensar en nuevas ideas y prácticas educativas en el contexto actual.

En concordancia con lo anterior, Martínez Bonafé (1994) escribió al respecto en Cuadernos de pedagogía un artículo denominado "Los olvidados: Memoria de una pedagogía divergente”, donde destaca:

Sin embargo, hoy en día se aprecia una obsesión, deliberada o inconsciente, por borrar el pasado colectivo, por desterrar de los discursos educativos actuales los referentes y las raíces, sobre los cuales han crecido y cristalizado las ideas y las prácticas pedagógicas más innovadoras de nuestro tiempo. (Martínez, 1994, pp. 58-65) 
Las pedagogías del siglo XX, también denominadas Escuela Nueva por su identidad de propósitos renovadores, se han identificado como un movimiento pedagógico heterogéneo, iniciado a finales del siglo XIX. Se constituye en una verdadera corriente pedagógica, con propuestas educativas de nuevo perfil, cuando al finalizar la Primera Guerra Mundial la educación fue nuevamente considerada esperanza de paz. Los pedagogos de la Escuela Nueva fueron reconocidos por lograr que la educación avivara la comprensión y la colaboración entre seres humanos de toda índole, etnia, género y culto, así como por una inclusión de todo tipo. De hecho, podría decirse que allí está el nacimiento de lo que hoy somos y construimos día a día.

Según el movimiento de la Escuela Nueva, era importante denunciar y modificar los vicios de la educación tradicional, la pasividad, el intelectualismo, la disciplinariedad y el enciclopedismo, con el propósito de definir un nuevo rol a los diferentes participantes del proceso educativo. Así pues, la educación del niño se basó en su desarrollo biológico. No hay aprendizaje efectivo que no parta de alguna necesidad o interés del niño, que debe ser considerado el punto de partida para el acto educativo. De ahí que la pedagogía tenga un contenido de reconocimiento de lo humano, como unidad de la razón y el sentir. Desde esta perspectiva se apuesta por una enseñanza científica y racional, que incluye el sentido, el significado y la emoción.

Respecto a la reciprocidad maestro-estudiante, se transita de la relación de poder-subordinación que se da en la escuela tradicional, a un vínculo marcado por una relación de afecto y confianza. Es más importante la forma en que se comporta el maestro que la palabra. El maestro será pues un auxiliar del libre y espontáneo desarrollo del niño. Además, se incorpora la autodisciplina y, por consiguiente, se cede autonomía a los que aprenden. Entre los representantes más reconocidos se encuentran Johann Heinrich Pestalozzi, John Dewey, María Montessori, Francesc Ferrer Guardia, Celestine Freinet, Jean Piaget, Ovide Decroly, Alexander Neill, Antón Makarenko, Robert Gagné, Paulo Freire, entre otros.

Si nos preguntáramos en el presente cuáles de las ideas planteadas por los pedagogos antes citados hemos alcanzado y qué queda por lograr, se podría afirmar que aún son sueños en proceso de realización, que están vigentes como ideales y contenidas en los modelos actuales. 


\section{Ideas de notables pedagogos del siglo XX}

Sin la intención de adentrarnos en la historia de la educación en la Modernidad, como tampoco abarcar todas las ideas y pedagogos ilustres de la época, pues no es el objetivo de este escrito, se analizará el trabajo de algunos de estos pedagogos para mostrar su vigencia y sus vínculos, según los diferentes campos pedagógicos que trataron, tales como la preocupación por la educación de niños con dificultades en el aprendizaje; la educación rural; las etapas del desarrollo cognitivo en niños; la conducta; el desarrollo tecnológico en la educación y los métodos de enseñanza y aprendizaje. Estos aspectos permitirán establecer las relaciones (lo común y lo diferente) que tienen entre sí estas ideas y con la pedagogía del siglo XXI, para mostrar la continuidad y comunidad de las ideas pedagógicas surgidas, así como para derivar de allí el vínculo que puede existir entre el conductismo y el constructivismo desde su surgimiento hasta la actualidad.

De manera sintética, esto será expresado desde las ideas, reflexiones y propuestas pedagógicas de algunos de los representantes de esta escuela moderna, los cuales siguen contando sus experiencias a través de las pedagogías actuales.

En primer lugar, se encuentra John Dewey (1859-1952), filósofo, pedagogo y psicólogo estadounidense. Las obras más destacadas de Dewey sobre la pedagogía son: Mi credo pedagógico (1867), Escuela y sociedad (1899), Cómo pensamos (1910), Democracia y educación (1925) y El niño y el programa escolar (1967). En su obra enfatiza en el método de enseñanza y los requerimientos que hace la vida a la escuela, de modo que se garanticen los procesos educativos cercanos a la experiencia contextualizada y vivenciada, para, desde allí, llevar a cabo la reflexión e indagación narrativa y desarrollar el sentido y el significado.

Dado que para Dewey los seres humanos son activos y actores creativos y requieren del hacer para aprender, su método de enseñanza está basado en los aspectos naturales y sociales del nińo, de manera que se refuerza la participación, las relaciones, la vivencia y la actividad con significado, así como el trabajo manual. En consecuencia, el método de enseñanza que propone consta de cinco aspectos en conexión lógica: (1) iniciar con una experiencia lo más alejada del ambiente escolar; (2) definir la dificultad de esa experiencia; (3) 
observar y dar una solución al problema estudiado; (4) formular una hipótesis para continuar con la experiencia y (5) someter la hipótesis a la reflexión narrativa, al tiempo que se observa el camino de indagación y problematización que recorre el niño.

Respecto a la escuela, la concibe como reconstrucción del orden social, un laboratorio donde todo gire alrededor de construcciones que involucren la experiencia, entendida como el ensayar y saber; la prueba y el conocimiento; el hacer no solo individual, sino también en las relaciones interpersonales, a partir de significados compartidos, donde el maestro es un orientador de los niños. El mayor empeño en su obra estuvo encaminado a transformar la institución educativa y al maestro para que facilitaran la dirección del niño en el aprendizaje. Así, en su escrito Mi credo pedagógico subraya que todo maestro debe comprender la dignidad de su profesión, la de ser un servidor social, destinado a mantener el verdadero orden social y asegurar el desarrollo social acertado.

Dada la actualidad de las ideas de Dewey sobre el directivo docente, vale la pena resaltar algunas de las que presenta en la obra citada. En la concepción de Dewey sobre la educación como un proceso de vida, la escuela es un espacio social no solo para recibir conocimientos como parte del acervo cultural de la humanidad y del contexto, sino que además es el asiduo lugar donde se debe reproducir la vida en sociedad. Entre sus preceptos están los referidos al maestro como orientador y al director, que en la actualidad se identifica con el directivo docente, quienes deben estar convencidos de la educación como forma de vida, como proceso de interacción y crecimiento a través de la experiencia. Para esto es necesario que conozcan el contexto y reflexionen sobre él, de modo que la escuela y su ambiente sean renovados a través de la participación y el hacer compartido, donde la pedagogía sea viva, apoyada por la ciencia y la investigación.

Por todos estos aportes, las ideas de Dewey se pueden identificar hoy con clases abiertas o escuelas sin muros, aprendizaje cooperativo, currículo centrado en problemas, educación basada en experiencia, entre otras.

En segundo lugar, se debe mencionar a María Montessori (1870-1952), educadora, médico psiquiatra y psicóloga italiana. Entre sus principales escritos 
están El método de la pedagogía cientifica (1909), El método Montessori (1912), Antropología pedagógica (1913), La autoeducación de la escuela elemental (1916), Método avanzado Montessori (1917), Ideas generales sobre mi método (1928), entre otros. En esta amplia obra la autora desarrolla ideas y prácticas que se basan en el enfoque científico de la pedagogía, de manera que parten de la observación y del método científico. Su pedagogía se centra en las relaciones y la creación de los ambientes propicios para el niño.

$\mathrm{Al}$ igual que Comenio, Montessori destaca que el proceso educativo debe ser natural y partir del interés y el esfuerzo personal. Por su formación, se dedica al estudio de los niños especiales, lo cual le permite reconocer la capacidad absorbente de la mente de los niños para aprender y los períodos sensibles en los cuales estos pueden desarrollar dicha habilidad con mayor facilidad. Asimismo, destaca la sensibilidad que tienen para relacionarse y comprender el mundo externo a través del conocimiento perceptivo, para lo cual considera necesario crear un ambiente educativo que permita la enseñanza dirigida a promover el aprendizaje.

En este sentido, resalta el papel del maestro como guía y generador de dichos ambientes educativos, así como la necesidad de enseñar los conocimientos científicos del momento y aplicarlos en los procesos de enseñanza. Pone su atención en la educación de los sentidos y la motricidad, para lo cual considera importante crear materiales didácticos basados en colores, formas, dimensiones y sonidos como apoyos. Por tanto, desarrolla las habilidades sensoperceptivas y motoras para lograr la observación y el movimiento.

En su didáctica se destaca la organización previa de la actividad según el interés de los niños, de manera que estos eligen la actividad que se va a realizar y la ejecutan guiados por el maestro; los niños se complementan en el trabajo grupal independientemente de las edades, para que los más grandes colaboren y apoyen en la enseñanza, además de lograr la sociabilidad y la colaboración. Asimismo, en su didáctica es fundamental aprender a escribir y leer, para lo cual acude al principio de su método natural, biológico y psicológico, que, precisamente, inicia por la escritura.

De esta síntesis se destacan las siguientes ideas y prácticas pedagógicas que, apoyadas en la biología, la psicología y la sociología, enriquecen a la peda- 
gogía en su continuidad de desarrollo hasta la actualidad: el estudio de los procesos cognitivos naturales de la infancia y sus períodos fundamentales de aprendizaje, que hoy son abordados por las ciencias cognitivas; el énfasis en las condiciones de los ambientes de aprendizaje para crear interés, significados y motivación desde las relaciones sociales; los apoyos externos y la satisfacción personal en el aprender; la eliminación del castigo como tal y el rol del adulto como guía y apoyo. Por último, reconoce el lugar de la investigación científica.

La vigencia de Montessori radica en sus ideas sobre la autonomía del niño en relación con su desarrollo, la convivencia y sus intereses en la vida cotidiana, así como en la utilización de métodos activos para aprender haciendo. También es de destacar las propuestas que hace de la organización de la clase y que rompen la linealidad del aula. Sobresale y prevalece la integración de los conocimientos científicos sobre el ser humano para su educación y desarrollo - que en la actualidad son temas de interés de la neuroeducación-, en relación con la motricidad, la percepción sensorial, la emoción, la razón desde la educación artística, la lectoescritura, las matemáticas y los métodos de la experimentación y la observación.

En tercer lugar, otro de los educadores que contribuyó con sus ideas pedagógicas a la Escuela Nueva, activa y social fue Célestin Freinet (1896-1966), francés, maestro de escuela rural y creador de la pedagogía popular. Entre su vasta producción pedagógica se hallan Las enfermedades escolares (1964), La psicología sensitiva y la educación (1950), Educación por el trabajo (1943), Los métodos naturales (1956), Por una escuela del pueblo (1969, póstuma) y La escuela moderna francesa (1957), obras donde Freinet muestra las limitaciones de la escuela tradicional respecto a la enseñanza y propone crear una escuela moderna.

Es reconocido por su posición ecléctica en la enseñanza, pues bebe de los avances de la Escuela Nueva, la psicología, la sociología y la política. Su propuesta tiene algunos principios que es importante resaltar, como son el activismo, la experimentación o tanteo experimental a partir de los conocimientos previos del niño; la comunicación, la cooperación y la participación en la vida escolar; la funcionalidad del trabajo, que, por una parte, consiste en que los niños resuelven desde sus conocimientos algunas necesidades con las 
cuales se relacionan y, por otra, conlleva el principio de la relación de la escuela y la vida, que requiere de ambientes que así lo posibiliten; y la creación de una red de información desde el trabajo de los niños, lo que se reconoce como la "escuela cooperativa".

Lo que se ha expuesto anteriormente tiene el propósito de mostrar la contribución que han hecho otras ciencias a la pedagogía y la enseñanza mediante la comprensión de los procesos del conocimiento que se producen en el ser humano. Así, se puede afirmar que la ciencia produjo cambios en la educación a través de diferentes vías, lo que a su vez condujo a que la educación fuera un camino para la propia educación de la ciencia y su cultura investigativa. Estos principios destacan que los contenidos de su enseñanza se basan en la confianza en la vida y en la naturaleza, con lo cual se desarrolla el interés por la acción; de ahí el principio del trabajo-juego.

Otro aporte importante de Freinet son las técnicas pedagógicas que desarrolla, las cuales consisten en un proceso o cadena de trabajos y juegos de trabajo, la elaboración de textos libres por los niños, hasta su impresión en forma de periódicos, revista escolar, biblioteca, planes de trabajo elaborados desde las asambleas de clase, donde se definen los intereses y las dificultades de los estudiantes, correspondencias, conferencias, ilustraciones, gráficas, entre otras. Todos estos ejercicios se realizan en redes de cooperación y de acuerdo con los problemas planteados de la vida y de interés de los niños. La forma organizativa es la cooperativa escolar, que permite la generación desde la cooperación de nuevas ideas y que los ubica en la acción como sujetos sociales.

La creatividad de esta pedagogía social no propone un método ni tampoco desarrolla una teoría como tal, sino una acción pedagógica que acerca a la vida y motiva a la acción. Es una pedagogía de la acción, que rompe con los esquemas totalizadores, autoritarios y disciplinarios del aula. Es una mirada opuesta alternativa a la pedagogía tradicional y a los currículos cerrados.

Hasta aquí se puede observar cómo las ideas pedagógicas de este período histórico mantienen en su esencia coherentes respuestas a la pedagogía tradicional, pero a su vez expresan la necesaria renovación de poner al sujeto que aprende en el centro de los procesos de enseñanza, de darle un papel activo y creativo, de eliminar el rol dominante del maestro y de un currículo organizado que debe cumplir. 
No obstante, paradigmas, enfoques, corrientes epistémicas y antropológicas de corte dualista han impedido o retrasado la asunción de estas utopías pedagógicas del siglo XX, que advierten la multidimensionalidad del ser humano y su carácter de sujeto activo que aprende en relación con su medio natural y social. En esta situación también inciden las políticas educativas centradas en la eficacia, la especialización, la profesionalización excesiva, entre otros aspectos, que alejan a los profesores de la investigación, la transformación e innovación educativa y de la motivación hacia nuevas ideas que retomen y actualicen la pedagogía centrada en el ser humano y no solo en el conocimiento, cuestión que colinda con enfoques tradicionales en la administración y la gestión educativa (Arana, 2018b).

En cuarto lugar, entre los educadores destacados en este período se encuentra Jean William Fritz Piaget (1896-1980). Este psicólogo y epistemólogo suizo es reconocido en el campo de la educación por el impacto que tuvo su investigación en la comprensión del proceso de conocimiento, construcción y desarrollo cognitivo en los niños, que concibe como parte de los procesos mentales que resultan de la maduración biológica y la experiencia ambiental.

Entre sus principales obras se hallan El lenguaje y el pensamiento en el niño (1931), El juicio moral en el niño (1932), El nacimiento de la inteligencia en el niño (1936), La construcción de lo real en el niño (1937), La psicología de la inteligencia (1947), Introducción a la epistemología genética (1950), La equilibración de las estructuras cognitivas (1975), entre otros. En su concepción constructivista está la esencia de su teoría del desarrollo cognitivo o de las etapas del desarrollo, resultado de la relación entre las etapas del desarrollo biológico y el desarrollo cognitivo del ser humano, para su actividad transformadora y autónoma. Por tanto, su trabajo hace contribuciones teóricas a la educación desde la psicología cognitiva.

Juan Delval (2002), profesor de la Universidad Autónoma de Madrid, discípulo de Piaget y dedicado al estudio de la conducta, señala que Piaget ofrece una visión del ser humano como un organismo que, al actuar sobre el medio y modificarlo, se modifica también a sí mismo. Considera el desarrollo de la inteligencia y la formación de los conocimientos — dos procesos para él indisociables - como un producto que se inicia en la actividad biológica de los seres humanos y en su capacidad de adaptación al medio. En conse- 
cuencia, para Piaget el conocimiento se origina en la acción transformadora de la realidad, ya sea material o mentalmente.

Además, señala que es importante insistir en que Piaget reconoce la necesidad de la investigación y la teoría como parte de las necesidades de la educación, pues permite encaminarla no solo desde el empirismo y la práctica educativa, sino también desde los procesos humanos internos, que explican la biología y la psicología humana, tal como hoy se estudian desde las nuevas ciencias cognitivas. Para Piaget, el conocimiento no es una copia de la realidad, como vendría a sostener el empirismo, ni es el producto de un despliegue de capacidades que ya posee el organismo, como sostenía el innatismo; es, por el contrario, el resultado de la interacción entre la dotación inicial con la que nacen los seres humanos y su actividad transformadora del entorno, una posición que se ha denominado constructivismo (Delval, 2002).

Por tanto, para Piaget la producción del conocimiento en el ser humano es un proceso adaptativo a una necesidad, a la realización de una acción, a una idea, para lo cual se apoya en los conocimientos que posee y desde allí da respuesta, es un proceso de reacción y no de repetición.

Esta perspectiva supera al tradicionalismo y avanza en los planteamientos de la época sobre cómo se aprende. Particularmente, algunos atributos pedagógicos de la teoría piagetiana que se destacan son la autonomía, el trabajo compartido, el trabajo en grupo, la labor del maestro como creador de ambientes de aprendizaje, el nińo como centro de la actividad pedagógica y la activación de los conocimientos previos para la creación de los nuevos.

La vigencia de Piaget en el constructivismo actual se manifiesta en tres tendencias: primero, el reconocimiento y la aceptación de su teoría en la psicología infantil, la cual se lleva a la práctica educativa. Segundo, la crítica sobre las limitaciones que se le atribuyen porque no aborda los factores culturales, emocionales, sociales ni pedagógicos de la psicología infantil. No obstante, esta crítica se debe a la incomprensión de sus justos propósitos epistémicos y de su interés por el estudio de los factores internos de la mente humana para crear conocimiento, así como a una pobre reflexión del contexto en que desarrolló su teoría. Tercero, el reconocimiento como antecesor de los estudios actuales de la neuroeducación, la que se basa en adelantos científicos sobre el cerebro humano que permiten ahondar en los procesos del conocimiento y la mente 
humana. Al respecto, el reconocido neurocientífico preocupado por la educación Francisco Mora (2008) afirma:

Los seres humanos no nacen con un cerebro que funciona como esponja y que absorbe, sin ningún sustrato previo, el conocimiento del mundo que los rodea. Por el contrario, el cerebro humano, al nacimiento, es ya un libro que lleva escritos muchos códigos de su futuro funcionamiento. De hecho, esos códigos son una tablilla de caras múltiples y deferentes sobre las que el medio que rodea al individuo escribe sus mensajes múltiples y diferentes. Y es la interacción entre cada tablilla del cerebro, cuyas características específicas solo permiten ciertas escrituras, y las escrituras mismas como cada ser humano concreto se construye y se hace a lo largo de su vida. (p. 39)

En correspondencia con Piaget, destaca, además:

Aprender algo nuevo significa, en términos neurobiológicos, cambiar el cerebro. De ahí se deduce, ya de entrada, que la neurociencia, y en particular la neurociencia cognitiva, es relevante para la educación.

Lo cierto es que la neuroeducación todavía alberga quizá más preguntas que respuestas, pues lo "neuro" es un campo de enorme expansión actual, tanto en la extensión de sus límites, como por la profundidad de sus contenidos. (Mora, 2008, pp. 191-192)

Por lo tanto, afirmar que la teoría de Piaget es limitada o aplicable, sin dar continuidad a la investigación, es una expresión del desconocimiento de los avances de la neurociencia.

En quinto lugar, es necesario abordar el trabajo de Burrhus Frederic Skinner (1904-1990), psicólogo, filósofo y escritor nacido en Pensilvania, Estados Unidos. Es un representante del pragmatismo filosófico y del funcionalismo psicológico en la educación, seguidor del psicólogo estadounidense John B. Watson, que formula la teoría psicológica de estímulo-respuesta. Su objeto de estudio se centra en la conducta humana observable, heredero de los estudios del fisiólogo ruso Iván Pávlov sobre el reflejo condicionado en animales, identificado como condicionamiento clásico, que busca modificar la conducta a través de un estímulo. Algunos de los trabajos de Skinner son El comportamiento (1938), Ciencia y conducta humana (1953), Conducta verbal (1957), The technology of teaching (1968), Más alla de la libertad y la dignidad (1971) y Sobre el conductismo (1974). 
Skinner aporta al conductismo la utilización del método científico de las ciencias naturales, con lo cual niega aspectos especulativos del empirismo y del psicoanálisis. Centró su investigación en el estudio de las conductas a través de su observación, lo cual le permitió fundamentar la teoría del condicionamiento operante. Según esta teoría, es posible modificar la conducta mediante estímulos, lo que Edward Thondrike denomina condicionamiento instrumental: como resultado de un estímulo se obtiene un comportamiento, tanto en animales, como en seres humanos. Precisamente, la principal contribución del conductismo al conocimiento del comportamiento humano es su teoría de que el condicionamiento es una forma de aprendizaje por asociación de estímulos.

El condicionamiento operante es una vía para el aprendizaje como cambio de conducta, ya sea a través del estímulo positivo o negativo, también por omisión y castigo, lo cual sucede al asociar el estímulo a una respuesta predeterminada o no, la cual tiene una consecuencia. El vínculo entre la conducta estimulada y la consecuencia como resultado deriva en una técnica para el aprendizaje concebido como cambio de conducta.

Los resultados del condicionamiento operante, denominados refuerzos de la conducta, se han clasificado de la siguiente manera: refuerzo positivo, cuando produce un suceso bueno o esperado; refuerzo negativo, por la omisión y el castigo; este último se da cuando ocurre un suceso malo y, por lo tanto, disminuirá la presencia de la conducta esperada. De esta manera se moldea la conducta por aprendizaje condicionado, lo cual se puede sintetizar en las relaciones entre el estímulo y la conducta refuerzo, que provoca los aprendizajes por adquisición o extinción. Entre los refuerzos positivos están: los premios, los reconocimientos, las distinciones, las felicitaciones, dejar de reñir, hacer una tarea asociada a una actividad o motivar a los niños a hacer lo que les guste. Ejemplos de refuerzos negativos por omisión sería no prestar atención, no contestar o no interactuar ante la conducta, y por castigo sería dar trabajo extra, regañar o negar lo que gusta.

Esta descripción permite identificar algunos aspectos de las contribuciones que hizo Skinner desde el conductismo a la educación: se puede aprender una conducta solo realizando la conducta; incluir en el programa de enseñanza 
el sistema de ayudas, tarea apoyada por el material; la repetición múltiple, el control, la objetivación, la secuencia de unidades y el autoaprendizaje, los juegos didácticos y las simulaciones; la importancia de los medios técnicos de enseñanza como las máquinas, los televisores, los libros, las guías, etc.; el maestro como el diseñador del programa; la constante actividad del estudiante; la individualización del aprendizaje y los resultados finales del aprendizaje en el cambio de conducta. Como se observa, se puede afirmar que la influencia de la obra de Skinner en la educación ha sido extensa, tanto en la enseñanza escolar como en los programas de formación empresarial y militar (Gros, 2001).

Se debe agregar que el conductismo también surgió como una respuesta a las insuficiencias de la enseñanza tradicional, por ejemplo, la aplicación incompleta del reforzamiento, entre ellos el castigo, el inadecuado orden y secuencialidad de los contenidos y materiales de instrucción, entre otros aspectos que no permitían que el aprendizaje provocara un cambio de la conducta, según su comprensión de aprendizaje.

Aprendemos actuando. Importa insistir en que el estudiante no absorbe pasivamente los conocimientos, limitándose a recibirlos del mundo que lo rodea. Conocer es actuar, operar, con palabras o sin ellas. Ahora bien, el estudiante no aprende tan solo mediante la acción [...]. Pero lo importante no es la mera frecuencia o la mera repetición, sino aquello que se está haciendo frecuentemente, repetidamente. (Skinner, 1969/1979)

Según González (2004), las consideraciones sobre la educación de Skinner pueden resumirse en cinco puntos: (1) los aprendizajes complejos están basados en aprendizajes simples; (2) las tareas deben plantearse subdivididas en sus partes más elementales para que puedan ser aprendidas; (3) el material que se va a enseñar debe subdividirse en fragmentos que permitan aportar con más frecuencia el feedback y el refuerzo al estudiante; (4) plantear una definición operativa del aprendizaje, es decir, formular los objetivos educativos en términos conductuales, enfatizando la especificación de las conductas observables que deben ser ejecutadas por los estudiantes y que deben ser observables y evaluables; (5) reconocer que cada estudiante sigue su propio ritmo de aprendizaje. Para este pedagogo del siglo XX, aprender conlleva una modificación permanente del comportamiento observable como fruto de la experiencia. 
Esto indica que la teoría conductista, también al reflexionar críticamente sobre la pedagogía tradicional, tiene aspectos comunes con el constructivismo: en primer lugar, se encuentra el énfasis en el aprendizaje a través de la conducta y el comportamiento, una vía pedagógica para conformar los rasgos de la personalidad. Sin duda, todo aprendizaje debe expresarse en el comportamiento humano, y en ello están presentes el reforzamiento y la norma, que permiten complementar los aprendizajes por significación, motivación y sentidos, para hacer consciente las actitudes en valores humanos y profesionales. En segundo lugar, otro aspecto común es la atención a los aspectos didácticos como el juego, los medios técnicos de enseñanza como máquinas, televisores, libros, guías y el lugar del maestro en el seguimiento sistemático al aprendizaje para la evaluación. Finalmente, en tercer lugar, se debe mencionar la atención que prestan a la enseñanza individualizada.

Uno de los alcances educativos de Skinner fue el diseño de una máquina para la enseñanza programada, con la intención de mejorar la enseñanza personalizada. La máquina programada fue pensada como un recurso técnico que permitió el desarrollo de la tecnología educativa de los años sesenta y setenta. Posteriormente, con el avance de la tecnología de la información y la comunicación, se introdujo la informática dirigida a la educación, a través de programas (software) y plataformas como las actuales, una informática aplicada a los procesos de enseñanza y aprendizaje que posteriormente se convertiría en la educación virtual. En la actualidad es un medio fundamental en los procesos de aprendizaje individual y de la enseñanza, y se continúa perfeccionando para corroborar la autonomía del estudiante y el lugar del profesor.

\section{Génesis, relaciones y tendencias entre el conductismo y el constructivismo desde las ideas pedagógicas del siglo XX hasta la actualidad}

Es necesario hacer notar que el conductismo como modelo pedagógico está presente, pese a las diferentes interpretaciones que rechazan los planteamientos centrados en el moldeamiento, el adoctrinamiento y su carácter heterónomo para buscar una conducta determinada. No se reflexiona que esta 
idea pedagógica surge en un contexto común al constructivismo y que, por lo tanto, su rechazo conjunto a aspectos de la pedagogía tradicional los lleva a retomar al ser humano como centro de la educación.

De esta manera, se puede afirmar que el conductismo comparte la esencia del constructivismo en sus orígenes pedagógicos. A la luz de las ideas pedagógicas actuales, son teorías complementarias en la formación integral del ser humano, pues no es posible desarrollar la autonomía sin la heteronomía, lo cual significa que la acción consciente del comportamiento del ser humano no solo es resultado de los valores compartidos por factores de significado y sentido, sino también de las exigencias de las normas establecidas desde los primeros ańos de la vida.

Esta complementariedad también se reconoce en los estudios del cerebro humano que realizan las ciencias cognitivas actuales llevadas a la educación, cuando afirman y comprueban que entre las formas de aprendizaje están: la memorización, que permite almacenar, recuperar y modificar información; la imaginación; a partir de la vivencia, la terapia, el ensayo y el error, y la imitación, en la cual el cerebro reproduce las acciones de otras personas a través de las neuronas especulares. De acuerdo con este último descubrimiento, uno de los más importantes de la neurociencia, las neuronas especulares reflejan como un espejo la conducta y la acción observada, considerada una representación de la realidad en el cerebro. Este último aspecto — que se relaciona con el ejemplo y el reforzamiento- y los mencionados anteriormente corroboran la complementariedad y complejidad del aprendizaje y la combinación de diferentes vías.

Pese a las diferencias entre el conductismo y el constructivismo pedagógicos que evidencian desde el inicio sus representantes en el siglo XX, se pueden identificar aspectos compartidos que manifiestan la continuidad y las tendencias transformadoras de la época. Entre estos puntos de convergencia se encuentra que ambas corrientes pedagógicas proponen que es posible incidir en la conducta y el comportamiento a través de la enseñanza y el aprendizaje; tienen interés en el aprendizaje para la vida y a lo largo de esta, para el hacer y no solo en el saber; aunque por caminos pedagógicos diferentes, buscan actitudes y aptitudes; sus propuestas metodológicas para la práctica educativa son complementarias cuando hay una comprensión integral del ser humano 
en lo bio-psico-social-cultural, que se muestra en el estudio de la motricidad, la percepción sensorial, la educación artística, la lectura, la escritura, el razonamiento matemático y la investigación; en los dos casos es fundamental el dato empírico que brinda la experiencia y el método científico; el análisis del contexto como elemento que se debe considerar en la enseñanza, asociado a las características sociales de la escuela para aprender en la vida, de la vida y para la vida; la incorporación de los nuevos conocimientos científicos sobre el ser humano y la sociedad; el rechazo a la homogeneización en el proceso de enseñanza y aprendizaje, y la necesidad de la individualización; la acción indirecta del maestro como orientador, guía y creador del ambiente de aprendizaje. Es de resaltar que estas dos miradas de la educación y del aprendizaje contemplan la autonomía de la individualidad y la subjetividad con la heteronomía de lo social y lo cultural del contexto.

Si bien la mayor diferencia reconocida entre estas ideas y prácticas educativas está alrededor del aprendizaje, pues en el conductismo este es el resultado de la asociación que se produce por la intervención del refuerzo, mientras que en el constructivismo el aprendizaje es el resultado de significados y sentidos, ambos parten de los conocimientos previos del estudiante. En este sentido, como se ha argumentado a lo largo del libro, solo un estudio profundo de los vínculos y las complementariedades de estas dos corrientes permitirá que las nuevas ideas pedagógicas y sus prácticas beban de lo mejor de ambas para la educación actual. Por eso es necesario insistir en que las propuestas de estas ideas, al surgir en un mismo contexto histórico como respuesta a la pedagogía tradicional y estar apoyadas en los nuevos conocimientos científicos sobre el ser humano, no pueden ser antagónicas, sino complementarias, aunque desde posiciones diferentes acerca del aprendizaje y de la didáctica de la enseñanza. Por tanto, son expresiones de los mismos problemas educativos.

Ahora bien, otro aspecto que se debate es el carácter activo y pasivo del estudiante en el aprendizaje. Sin embargo, es cuestionable, pues en todo proceso de aprendizaje el cerebro como centro del conocimiento humano es activo, lo que difiere es la acción del sujeto ante el aprendizaje, la cual depende del punto de partida elegido y de las formas en que se despliegue la acción del conocer: la motivación, el interés, las emociones, la asociación, el estímulo y la norma, aspectos que, por demás, están presentes en ambos modelos de ense- 
ñanza. Así mismo, es importante la interacción con el entorno y los ambientes que se deben crear, encaminados de maneras diferentes: las relaciones interpersonales, la responsabilidad individual y el ambiente como un todo de la cultura institucional o creada como mecanismo de reforzamiento.

De acuerdo con lo señalado, afirmar que el conductismo consiste en producir una conducta observable, mientras que para el constructivismo es un significado, constituye un planteamiento incompleto, puesto que en el ser humano tanto la emoción como la razón pueden aprenderse por diferentes vías, que por demás en la vida se complementan. Así, la enseñanza en busca de un comportamiento observable también desarrolla un significado en el aprendiz, por lo que es necesario combinar acciones pedagógicas en la formación, y más aún en aquellas profesiones que lo requieran como la militar. No es posible dejar de considerar que la educación es la vía que tiene la sociedad para que la cultura llegue a las personas, y que son disímiles las estrategias para lograrlo.

Además, cabe resaltar que en ambas miradas y prácticas está la dialéctica entre la enseñanza y el aprendizaje, que muestra que las personas aprenden constantemente de la vida, de todo lo creado de generación en generación. Se aprende de un libro, de una obra de arte o de una tecnología porque en ellos median otras personas con sus conocimientos y métodos para enseñar, para dar a conocer. Se aprende de quienes por algún medio nos enseñan de diferentes formas. Asimismo, cuando se enseña, se aprende, ya que enseñar es inherente al aprender, como el aprender es resultado de enseñar. No puede ser lo uno sin lo otro en una sola vía. Incluso en ocasiones se enseña a desaprender para superar aprendizajes anteriores y, por negación, la posibilidad de no aprender. En este sentido, se debe enfatizar que únicamente con conocimientos, por medio del proceso de enseñanza-aprendizaje, es posible crear nuevos conocimientos.

\section{Reflexiones de cierre sobre la mixtura del modelo pedagógico militar}

Por lo anterior, se ratifica la necesidad de ir a la historia, a la génesis del conductismo y del constructivismo para, desde allí, encontrar en sus propuestas esenciales lo común, no solo las diferencias. Por eso el enfoque histórico gené- 
tico desde la dialéctica permite hallar lo que justifica la relación de estas ideas en un modelo pedagógico complejo como es el de la profesión militar.

Es así que acudir a la historia de la educación es comprender la evolución de la cultura escolar, y en ella los modelos pedagógicos, pues se trata de observar las representaciones e ideales que están en la realidad y que se construyeron en un proceso histórico que actúa en el presente. Por ello, para pensar y proponer hoy un modelo pedagógico que interactúe con la cultura institucional, hay que retomar las particularidades de la educación militar en su pasado reciente, puesto que en ella se concentran rasgos educativos marcados por las tradiciones pedagógicas de la formación militar, ceñidas a dos enfoques que tratan al ser humano de manera diferente, pero que son complementarios desde su génesis hasta su incidencia en las necesidades del aprendizaje humano: el constructivismo y el conductismo.

Para plantear esta hipótesis fue necesario ir a la historia de estas ideas pedagógicas y comprender su génesis. Esto permitió observar aspectos comunes y complementarios que dan fundamento a la presencia de ambas corrientes en la conformación de un ideal pedagógico, particularmente, en la educación militar. En este sentido, la mirada no es solo de lo pedagógico, sino también de la respuesta social a una formación profesional específica.

Es importante insistir en que la vigencia o actualidad de las ideas de estos destacados educadores, formados desde diferentes profesiones, no está en su expresión exacta, sino en la manutención de su esencia, enriquecidas por el contexto cultural actual. Pero también en la solidez de sus conexiones, las cuales ofrecen focos de generalidad sobre la enseńanza y el aprendizaje.

Lo que se ha expresado hasta este punto es resultado de la reflexión no solo pedagógica en sí misma, sino también de la historia de la educación, de donde se comparten tendencias que incluyen contenidos de estudio como la cultura de las instituciones educativas, en contextos concretos como el de la Escuela Militar de Cadetes “General José María Córdova” (Esmic). De esta manera, desde sus tradiciones, representaciones y realidades actuales, devenidas del contexto cultural y social, es posible pensar y proponer coherentemente una cultura educativa que contenga el modelo pedagógico. Este ejercicio reflexivo permite sustentar el modelo pedagógico teórica e históricamente, como afirma 
Alarcón (2014) al referirse a los cambios y las nuevas tendencias de la historia de la educación, de tal manera que se eliminen los aspectos "pedagogizantes" y absolutamente descriptivo-anecdóticos que impiden la comprensión de los desarrollos educativos actuales desde el pasado, para pasar a una reflexividad pedagógica y educativa crítica, desde los contextos pasados a la actualidad. Es decir, darle

un sustento teórico mucho más profundo y denso que explicite los procesos educativos que han tenido lugar en las sociedades a través del tiempo. Una historia que hoy resulta fundamental para superar el presentismo en que han caído la investigación educativa y pedagógica, cuyos estudiosos no pueden perder de vista que el hecho educativo es un fenómeno social estrechamente ligado al conjunto de las acciones del hombre en sociedad y por tanto posee una historicidad. (Alarcón, 2014, p. 1)

En este punto cabe enfatizar en la continuidad y unidad dialéctica de las ideas pedagógicas, expresadas en los estudios de la neurociencia en la educación. Específicamente, la necesidad de crear puentes epistémicos y metodológicos entre los conocimientos pedagógicos y neurocientíficos, para que los nuevos conocimientos sobre los procesos cerebrales y sus mecanismos neurocognitivos se transfieran a los procesos de enseñanza para el aprendizaje. De esta manera, no solo es posible evitar que los enfoques, las miradas y los análisis de estos conocimientos se queden en la mera interpretación, sino que además se pueden crear los escenarios propicios para que las emociones, los ambientes y la conducta operen coherentemente en el interior del ser humano y se manifiesten en lo exterior, dependiendo de los ambientes, a través del comportamiento y la conducta. En opinión de Skinner:

El conductismo, como lo conocemos, morirá a la larga, no por su fracaso, sino por su éxito. Como filosofía de la ciencia, necesariamente va a cambiar cuando cambie una ciencia de la conducta y los problemas actuales que definen al conductismo sean resueltos totalmente. (Skinner, 1969/1979, p. 240)

Muchos investigadores de estos temas sostienen que actualmente el estudio de la conducta humana se desarrolla en las neurociencias, especialmente a través de los conocimientos sobre la manera como funciona el cerebro, las redes neurales, la emoción, la cognición y la memoria, solo por 
citar algunos campos que permiten un acercamiento a la comprensión del ser humano y de la vida.

Sin embargo, la educación aún tiene limitaciones para aceptar los avances de las ciencias del comportamiento y la conducta, ya que se ha separado de ellas los valores humanos como resultado de enfoques disciplinares que restringen la comprensión de la naturaleza humana. Por lo tanto,

la superación de estos obstáculos requiere de una construcción interdisciplinaria genuina que incluya en sus debates cuestiones ideológicas, epistemológicas, metodológicas y éticas en un marco de referencia sistémico, con cautela, respeto al esfuerzo de diferentes disciplinas y orientados a abordar problemas educativos concretos definidos por las propias comunidades que los identifican e intentan resolver. Todo ello es además condición necesaria previa a todo esfuerzo orientado al diseńo de propuestas concretas de enseñanza, que aún constituye un área que debe ser desarrollada. (Lipina, 2016, p. 13)

Otra de las brechas y limitaciones que existen entre la neurociencia y la educación es la falta de referencia sobre el comportamiento y los procesos cognitivos del aprendizaje, en relación con los aspectos biológicos del proceso de enseńanza, lo cual impide la integración de las neurociencias al conocimiento pedagógico.

También existe desarticulación entre las diferentes ciencias y entre los diferentes enfoques o modelos educativos. Unos resaltan el aprendizaje desde la emoción y el significado, pero no desde el comportamiento en toda su dimensión de estudio. Otros lo hacen desde lo normativo y conductual. Sin embargo, en ambos casos se separa la relación de lo biológico, lo cognitivo y lo comportamental.

Solo la integración del conocimiento para comprender el desarrollo del ser humano permite construir "puentes" (Bruer, 2016) que conecten y eliminen los obstáculos epistémicos y de método de producción de conocimiento, así como acabar las "brechas" existentes entre la epistemología y el método. Estos puentes permiten además superar la "visión de túnel" disciplinar y el enfrentamiento y carencia de cooperación epistémica y metodológica. Así, brecha y puente son dos conceptos que han estado presentes en las distintas consideraciones sobre los potenciales vínculos entre ambos conocimientos, los cuales 
irán desarrollando a la neuroeducación y crearán la posibilidad de que la enseñanza se encamine hacia un aprendizaje integral del ser humano.

Una comprensión desde este enfoque permite eliminar progresivamente los llamados reduccionismos, ya sea que se deban a la carencia de comprensión del método científico, específicamente de la dialéctica entre el todo y la parte en la búsqueda de la esencia del fenómeno, o que sean consecuencia del reduccionismo extremo eliminativo, que entiende que las partes pueden negar el todo. Así es como cada sistema de conocimientos teme ser sustituido por otro, o se niega la complementariedad de estos: lo biológico es un enfoque estrecho de la neurociencia, y lo cognitivo-conductual de la psicología, mientras que la enseńanza y el aprendizaje lo es de la pedagogía o de las ciencias de la educación. Se trata entonces de un asunto que impide la creación de puentes epistémicos y metodológicos —en este caso entre los enfoques conductista y constructivista - que eliminen la oposición y exclusión entre ambos, devenidos de la conexión entre lo biológico y lo cultural.

Así, esta perspectiva permite que los avances de la psicología cognitiva, la biología y las neurociencias —entre otras que forman parte de las ciencias cognitivas - sobre el funcionamiento del sistema nervioso central y del cerebro se conecten con las prácticas pedagógicas que los maestros desarrollan rutinariamente en sus aulas. De esta manera, dichos conocimientos forman un marco teórico con el que pueden armonizar el proceso de enseñanza-aprendizaje con el desarrollo del cerebro de sus estudiantes y su integralidad humana.

La neurociencia cognitiva ha sido y es la que probablemente mayores contribuciones potenciales ha hecho durante la última década a la educación. Como parte de sus objetivos, plantea el estudio integrado de las bases neurales de las representaciones mentales involucradas en diferentes procesos cognitivos, emocionales, motivacionales y psicológicos. Muchos de sus modelos conceptuales provienen de la psicología cognitiva, dedicada al estudio de los procesos mentales que subyacen al comportamiento observable, así como a las emociones, con lo cual ha avanzado hacia la integración de las perspectivas constructivista y conductista. Es decir, la neurociencia cognitiva estudia el proceso de desarrollo humano desde lo biológico, cognitivo-emocional y el comportamental-conductual, de tal modo que incluye los conocimientos 
genético, molecular, celular y de las redes neurales, además incorpora los avances sobre los procesos cognitivos y comportamentales implicados en la conducta individual y los comportamientos sociales en diferentes contextos de desarrollo.

En consecuencia, el maestro no solo debe tener conocimientos de su disciplina, de psicología cognitiva y de pedagogía, sino que también debe incorporar a su formación y actualización permanente los conocimientos de punta sobre cómo se desarrolla el sistema nervioso central y el cerebro desde la enseñanza, para que procesos como el cálculo, la memoria y la atención, así como las conductas de sus estudiantes, respondan en el aula a un proceso de desarrollo natural de sus estructuras cognitivas. Además, de esta manera también podrá romper paradigmas establecidos, únicos y contradictorios, que impiden pasar los puentes y superar las brechas entre modelos cerrados y desvinculados en la pedagogía. En últimas, para concluir, se trata de que el maestro incorpore la reflexividad pedagógica, la dialéctica del continuum del conocimiento y la adecuación a los contextos formativos. 